\title{
The Effects of the Environmental Design Instruction on the Students' Gymnastics Skill Refinement
}

\author{
Han Chen \\ West Virginia University
}

Follow this and additional works at: https://researchrepository.wvu.edu/etd

\section{Recommended Citation}

Chen, Han, "The Effects of the Environmental Design Instruction on the Students' Gymnastics Skill Refinement" (2012). Graduate Theses, Dissertations, and Problem Reports. 201.

https://researchrepository.wvu.edu/etd/201

This Dissertation is protected by copyright and/or related rights. It has been brought to you by the The Research Repository @ WVU with permission from the rights-holder(s). You are free to use this Dissertation in any way that is permitted by the copyright and related rights legislation that applies to your use. For other uses you must obtain permission from the rights-holder(s) directly, unless additional rights are indicated by a Creative Commons license in the record and/ or on the work itself. This Dissertation has been accepted for inclusion in WVU Graduate Theses, Dissertations, and Problem Reports collection by an authorized administrator of The Research Repository @ WVU.

For more information, please contact researchrepository@mail.wvu.edu. 
The Effects of the Environmental Design Instruction on the Students' Gymnastics Skill Refinement

\title{
Han Chen
}

\author{
Dissertation submitted to the \\ College of Physical Activity and Sport Sciences \\ at West Virginia University \\ In partial fulfillment of the requirements \\ For the degree of \\ Doctor of Philosophy \\ In \\ Kinesiology \\ Major in Physical Education Teacher Education \\ Andrew Hawkins, Ph.D., Chair \\ Robert Wiegand, Ed.D. \\ Sean Bulger, Ed.D. \\ Richard Walls, Ph.D. \\ Daniel Hursh, Ph.D. \\ Department of Coaching and Teaching Studies \\ Morgantown, West Virginia \\ 2012
}

Keywords: Direct Instruction; Environmental Design Instruction; Gymnastics Skill Refinement

Copyright 2012 Han Chen 


\begin{abstract}
The Effects of the Environmental Design Instruction on the Students' Gymnastics Skill Refinement
\end{abstract}

Han Chen

The study compared the effects of Direct Instruction (DI) with DI+Environmental Design Instruction (EDI) on the refinement of both simple and difficult gymnastics skills refinement. Four boys aged six to eight with two years of gymnastics training experiences participated in the simple skill experiment (running tuck jump on the springboard). Four boys aged 11 to 13 with more than three years of gymnastics training experiences participated in the difficult skill experiment (mushroom circles). Three dependent variables were measured in the experiment of running tuck jump and they were: (1) the participant's hip angle while they jumped at the highest point, (2) the participant's back point while they jumped at the highest point, and (3) the participant's jump height. Two dependent variables were measured in the experiment of mushroom circles and they were: (1) the participant's torso angle and (2) the participant's arm angle. Alternating treatments single-case research design was used for both experiments in which two treatments were alternated across daily sessions with one treatment in effect for each day. The results showed that in the experiment of running tuck jump, DI+EDI worked better for participants in bringing knees closer to their chest when they jumped at the highest point. The DI+EDI also helped the participants jump higher compared with DI. However, DI+EDI caused a more negative effect on the participants' back angle. In the experiment of mushroom circles, DI+EDI was not better or even worth than DI in helping participants' body extension and opening arm angle, although participants' form did not have an improving trend in either of the teaching methods. 


\section{Table of Contents}

Abstract

Chapter 1 Introduction

Introduction

The Problem 5

Statement of the Problem 5

Scope of the Study $\quad 5$

$\begin{array}{ll}\text { Hypothesis } & 7\end{array}$

$\begin{array}{ll}\text { Basic Assumptions } & 7\end{array}$

$\begin{array}{ll}\text { Limitations } & 8\end{array}$

Definition of Terms $\quad 8$

Significance of the Study $\quad 9$

$\begin{array}{ll}\text { Chapter 2 Literature Review } & 10\end{array}$

$\begin{array}{ll}\text { Literature Review } & 10\end{array}$

$\begin{array}{ll}\text { Direct Instruction } & 10\end{array}$

$\begin{array}{ll}\text { Information Processing Theory } & 13\end{array}$

$\begin{array}{ll}\text { The Dynamic System Theory } & 15\end{array}$

$\begin{array}{ll}\text { Ecological Task Analysis } & 19\end{array}$

Behavior Analysis in Sports Performance $\quad 25$

Chapter 3 Method 31

$\begin{array}{ll}\text { Method } & 31\end{array}$

$\begin{array}{ll}\text { Participants } & 32\end{array}$

Dependent Variables $\quad 33$ 
Independent Variables $\quad 34$

Direct Instruction $\quad 35$

Combination of DI and EDI (DI+EDI) 35

$\begin{array}{ll}\text { Research Design } & 37\end{array}$

$\begin{array}{ll}\text { Procedure } & 37\end{array}$

Data Analysis $\quad 39$

Chapter 4 Results $\quad 42$

Experiment 1 (Running Tuck Jump) 42

Experiment 2 (Mushroom Circles)

Chapter 5 Discussion 63

$\begin{array}{ll}\text { References } & 69\end{array}$ 


\section{CHAPTER ONE}

\section{Introduction}

Although National Association for Sport and Physical Education (NASPE) standards were developed more than 25 years ago, instructional skill has always been important for Physical Education Teacher Education (PETE) Programs. Standard four of the most recent NASPE standards ("National Association for Sport and Physical Education (NASPE).", 2008) indicates that "physical education teacher candidates use effective communication and pedagogical skills and strategies to enhance student engagement and learning" (p.2).

PETE researchers have been trying to identify the characteristics of teaching effectiveness. Studies in process and product research indicate that certain teacher and student behaviors are associated with student achievement. These studies (French et al., 1991; French, Rink, \& Werner, 1990; Gusthart \& Sprigings, 1989; Metzler, 1989; Rink, French, Werner, Lynn, \& Mays, 1992; Silverman, 1985, 1991; Werner \& Rink, 1989) lay a foundation for "Direct Instruction (DI)". The key elements for effective teaching in DI include: (a) reviews to check for understanding, (b) stating the objective and purpose of the lesson, (c) a clear presentation of new material including cues, demonstrations, and strategies such as questioning to check for understanding (CFU), (d) practice opportunities in which students are accountable, engaged, and successful, (e) teacher supervision with feedback, and (f) a closure with a review and final CFU (Graham, 2008;

Rosenshine \& Stevens, 1986)

In youth sports settings, many coaches use direct coaching styles in their instruction which includes most of the characteristics of DI. Their coaching behaviors of DI involve 
the coach's explanation of a skill or drill, followed by athletes' performance with the coach's observation, and the coach's critique for the evaluation (Lockwood \& Penman, 2008).

Relating to information processing theory, the DI concept has been supported as effective teaching and was viewed as one of the strongest variables relating to student achievement in teaching reading and mathematics at the elementary level (Rink, 2002). In the physical education field, Rink (2002) concluded, based on the previous research, the more the instruction related to the characteristics of DI, the more the students learned.

However, DI is not a one-fits-all model. Recommended concepts within DI include: (a) teach lesson content with a hierarchical structure, (b) focus the lesson content on the basic skill, and (c) be concerned about learning efficiency (Rink, 2002). Joyce, Weil, \& Calhoun (2009) indicated that DI "plays a limited but important role in a comprehensive educational program." In fact, there was caution that DI should not be used all the time, for all students, and for all educational objectives (Joyce et al., 2009).

The dynamic system theory views the human as the one comprised of many subsystems which are independent but also interact with each other (Davids, Button, \& Bennett, 2008). Newell (1986) proposed three categories of constraints. They are: (a) organismic constraints, (b) environmental constraints, and (c) task constraints. These three categories of constraints interact for a certain organism to produce the best pattern of coordination and control for a given activity. Organismic constraints include structural constraints (e.g., body weight, height) and functional constraints (e.g., synaptic connections). Newell (1986) defined environmental constraints as constraints external to 
the organism (e.g., gravity, temperature, light). Task constraints focus on the activity goal and the imposed specific constraints.

Based on Gibson's ecological psychology (as cited by Davis \& Burton, 1991), Davis and Burton (1991) proposed an Ecological Task Analysis (ETA) approach as opposed to traditional task analysis such as information-processing task analysis and developmental task analysis. ETA can make the tasks easier to ensure student success or make it harder to provide challenge. One of the strengths of ETA is the linking of the task goal and the constraints of the environment and the performer. Davis and Burton (1991) went on to indicate that the use of performer-scaled dimension can be used to link all the three factors (task, environment, and performer). An example of performer-scaled dimension would be selecting a ball diameter for dribbling with one hand, then identify the performer's hand width, using the same measurement unit as the ball diameter (e.g., inch), and dividing the ball diameter by the performer's hand width to obtain a performer-scaled ratio. Setting environment was also proposed in the Davis and Burton (1991) ETA model. They indicated that an instructor should establish the environment and use explanation and demonstration to help students understand the task goals.

The dynamic systems theory facilitates research on "Environmental Design Instruction" (EDI; Sweeting \& Rink, 1999). Some researchers referred to it as taskenvironmental design (Rukavina \& Foxworth, 2009) while others simply called it an intervention strategy (Scott, Scott, \& Goldwater, 1997).

The concept of EDI is to use an indirect teaching approach to elicit quality performance. Sweeting and Rink (1999) examined the effect of EDI by placing swamp 
pictures on the mat in front of the performers to jump over to improve the process and product results. They found that the environmental designed condition had more positive effects on younger and less-skilled students. Rukavina and Foxworth (2009) examined the effects of an EDI taught by pre-service teachers by putting obstacles in front of the students to jump over to elicit tuck and extension movement. They found that both direct instruction and indirect instruction (EDI) worked and suggested using combined instruction. Scott, et al. (1997) conducted EDI by asking an elite pole vault athlete to break a photoelectric beam with his hands when he was at the take-off moment. The photoelectric beam was gradually increased following successful breaks for multiple times, until the athlete reached the max arm extension height at the take-off moment. The results indicated that the EDI could help increase the height of arm extension which resulted in increasing bar height clearance.

There is limited research which has been done in EDI. Some research examined the effects of different types of equipment (e.g., ball size, ball color) on ball catching (Belka, 1985; Isaacs, 1980; Morris, 1976; Strohmeyer, Williams, \& Schaub-George, 1991), while others examined the effects of body position, specific situation (e.g., throwing baseball while in active or inactive situation), and the equipment (e.g., ball size, ball mass) on the participants' throwing motion (Barrett \& Burton, 2002; Breslin et al., 2009; Cross, 2004; Southard, 1998).

Physical educators are still continuing to explore ways for effective teaching and coaching. Previous research has been conducted to investigate the effects of intervention for effective teaching including verbal feedback, public posting, goal setting, behavioral package, video feedback, form training, and applications of the matching law (Allison \& 
Ayllon, 1980; Anderson \& Kirkpatrick, 2002; Boyer, Miltenberger, Batsche, \& Fogel, 2009; Brobst \& Ward, 2002; Kladopoulos \& McComas, 2001; Mellalieu, Hanton, \& O'Brien, 2006; Romanowich, Bourret, \& Vollmer, 2007; Smith \& Ward, 2006; Vollmer \& Bourret, 2000; Ward \& Carnes, 2002). Although EDI model is not new, very few studies have tested its effectiveness. Also, previous research only compared the effect of DI and EDI on the standing long jump (Sweeting \& Rink, 1999), and examined the effect of DI+EDI on pole vaulting (Scott et al., 1997). Further, little research has compared the effects of DI with DI+EDI although scholars support using a combined approach (Rukavina \& Foxworth, 2009). Thus, the current research expanded the previous studies by comparing the effect of DI with DI+EDI on simple and difficult gymnastics skills refinement.

\section{The Problem}

Statement of the problem. The study compared the effects of the DI with DI+EDI for simple and difficult gymnastics skills refinement.

Scope of the study. Two experiments were conducted in the study. The participants in the first experiment were four male gymnasts between the ages of six and eight. The participants in the second experiment were four male gymnasts between the ages of 11 and 13. Participants are members of West Virginia Gymnastics Training Center. The research session was six weeks. The participants practiced four times each week with each practicing day lasting for four hours. The first experiment compared the effects of DI with DI+EDI on a simple gymnastics skill refinement, while the second experiment compared the effects of DI with DI+EDI on a difficult gymnastics skill 
refinement. The DI was comprised of (a) coach demonstration of the to-be-learned skill, (b) coach provision of the cues for skill, and (c) coach provision of feedback following participant's skill performance. EDI was set up for both experiments. In the experiment of running tuck jump (Experiment 1), an adjustable hurdle was used for EDI. The adjustable hurdle was placed in front of the springboard at a point where a vertical line was drawn from an elite gymnast's hip point at the peak point when he performed the demonstration. The hurdle was adjustable (could be raised or lowered). The participants' body height was measured by measuring the distance between the participant's toe points to the floor while jumping at the highest point. Each participant was taught by DI first. The height of the hurdle was set up according to the participants' requirements and was at least three centimeters higher than the previous mean body height for Adam, Harry, and Mark. It was at least one centimeter higher (with one exception session) than the previous mean body height for Tim when they were taught by DI.

In the experiment of mushroom circles (Experiment 2), a 90 degree bent plastic tube was inserted with one side into a hitting tee's ball holder. A string was hung from the top of tube. The string could be raised or lowered. The tee could be moved closer or farther away from the mushroom. The hitting tee and the string were adjusted for each participant to a point where each participant's toes could almost touch the string while their circles' position was in front of the mushroom. The positions of the tee and the string were recorded and saved for EDI set up.

The experiments were video recorded, and skill performance was analyzed using Dartfish software. 
Hypothesis. Previous research has examined the effects of EDI on the simple skill (standing long jump) (Sweeting \& Rink, 1999) and the results supported the effects of EDI on improving both process and product of the skills. However, the effects of DI+EDI on simple skills have not been examined although we assume that the effects of DI+EDI would be better than the effects of EDI. Thus, the first hypothesis is that DI+EDI compared with DI will have a better and positive effect on participants' simple gymnastics skill refinement.

A Previous study also evaluated the effects of EDI on the difficult sports skill (pole vaulting) (Scott et al., 1997) and the results indicated the positive effectiveness of EDI on increasing the bar height clearance. However, the study recruited an internationallevel pole vaulter. Thus, although EDI had positive effects on improving internationallevel player's difficult skills like pole vaulting, it had not been documented that the effects of EDI would also have the positive effects on improving low-level player's difficult skills. Based on the author's previous training and coaching experiences, we anticipate that EDI (or DI+EDI) compared with DI will not have better effects on improving low-level player's difficult skills. Thus, the second hypothesis is that DI+EDI compared with DI will have less or no effects on the participants' difficult gymnastics skill refinement.

\section{Basic assumptions.}

1. The research session had a sufficient number of trials for skill acquisition.

2. Dartfish software provided accurate skill data.

3. The camera provided accurate images of skill performance. 
4. Consensual agreement between observers provided accurate skill analysis

\section{Limitations.}

1. Due to the limited number of participants in the study, the results were carefully generalized.

2. The research only conducted EDI in gymnastics teaching; thus the application of the effects of the EDI on other sports should be cautioned.

3. The participants in the current study were experienced gymnasts, and their ages were between six and eight for the first experiment (running tuck jump) and between 11 and13 for the second experiment (mushroom circles). All participants had practiced gymnastics for more than two years. The results may not apply to novice gymnasts or people whose ages were not within this range.

4. The mean dependent variables for each session will be generated (five sets of running tuck jump for the Experiment 1, and three sets of five circles on the mushroom for the Experiment 2) and analyzed in the study. However, looking at each session's data points would yield patterns different than the analysis of means.

\section{Definition of terms.}

Mushroom circles. The participant places weight on both hands alternatively on the mushroom while the legs are doing circles around the mushroom.

Running tuck jump on the springboard. The participant runs a certain distance, then places both feet on the springboard. The participant then swings his arms to jump straight up and brings his knees towards his chest. 
Significance of the study. Previous research on EDI only examined its effects on learning the standing long jump and pole vault. The limited research in EDI leaves scholars unclear about its effectiveness for skill-learning in other sports. Also, few studies examined the effect of DI+EDI or compared the effect of DI with DI+EDI although some scholars supported using the combined approach in teaching skills (Rukavina \& Foxworth, 2009). Thus, this study tested the effectiveness of DI+EDI in teaching both simple and difficult gymnastics skills. The research also compared the effects of the DI with DI+EDI on both simple and difficult gymnastics skills refinement. 


\section{CHAPTER TWO}

\section{Literature Review}

\section{Direct Instruction}

In the 1960s, Engelmann and his colleagues created the Direct Instruction model (DI). The first research was published implementing the model of Direct Instruction System for Teaching and Remediation (DISTAR) which was used to address reading, language, and math (Engelmann \& Bruncer, 1969; Engelmann \& Carnine, 1969; Engelmann \& Osborn, 1969). According to Joyce, et al. (2009), DI refers to a pattern of teaching that "consists of the teacher's explaining a new concept or skill to students, having them test their understanding by practicing under teacher direction (that is, controlled practice), and encouraging them to continue to practice under teacher guidance (guided practice)"(p.369).

Joyce and his colleagues (2009) identified principles of direct instruction based on previous research. They indicated that the direct instruction model is comprised of five phases of activities: orientation, presentation, structured practice, guided practice, and independent practice.

At the beginning of the class, teachers should set up a lesson framework and direct students to the new materials. Joyce et al (2009) indicated that during this phase, the teacher should (a) provide lesson objectives, (b) teach lesson content, and (c) describe the lesson procedure including students' accountability. 
The instruction then can begin with presenting a new skill or concept. According to Rosenshine (1985) effective presentation includes: (a) presenting materials in small parts to master small steps at one time; (b) providing many examples of new skills or concepts; (c) providing demonstration of the to-be-learned task; (d) avoiding digression, staying on topic; and (e) re-explaining difficult points.

Rosenshine (1985) indicated that effective teachers should CFU after they present the task. The characteristics of the CFU includes (a) ask convergent instead of divergent questions; (b) make sure that all students have chance to respond; (c) ask questions within students" "reach" a high percentage of the time (75 to 90 percentage); and (d) avoid nonacademic questions.

During structured practice, the teacher leads students to practice each step. The students in this phase usually practice in groups. The teacher's job is to provide feedback based on students' response in an effort to reinforce accurate responses and correct errors. The teacher, through providing feedback, can then be sure that the students know the content knowledge and are ready for the next phase.

Phase four is guided practice. The students' job in this phase is to practice on their own with support, which gives teachers opportunities to assess students' abilities for performing tasks. The teacher in this phase will also monitor students' practice and provide corrective feedback if necessary.

Independent practice is in phase five. The students start their independent practice when they reach 85 to 90 percent of accuracy level in guided practice phase. The purpose of independent practice is for students to achieve fluency and maintain retention. The 
students practice by themselves without support and with delayed feedback. The teacher assesses students' work soon after completion to see if their accuracy level has maintained and provides corrective feedback when necessary.

According to Rink (2002), process-process studies deal with some assumptions related to satisfactory process characteristics during the instruction (e.g., if students' response is assumed to be good, then studies will try to identify what teachers do to produce more students' response). This kind of studies dominated the research in the latter part of 1950 and into the 1960s. The process-process studies focused on instruction characteristics (e.g., more students' talk is better and what teachers do can elicit the students' talk), which failed to relate to student learning. The emergence of processproduct studies aimed to connect what teachers did to what students learned in the classroom. Rosenshine and Furst (1971) synthesized five process variables that related to student achievement. They were: (a) opportunity to learn; (b) teacher's task orientation; (c) the variability of instructional techniques; (d) teacher enthusiasm; and (e) clarity of the presentation. Rink (2002) believed that research of teacher effectiveness in the 1970s let researchers realize that the students are more likely to learn certain content when they are taught directly. She went on to indicate that the idea of direct instruction includes highly active teaching, focused learning, and student accountability. Rink (2002) also specifically discussed direct instruction in physical education and stated the principles for direct instruction in physical education. Most of the principals are similar to those of Joyce et al. (2009). They are: (a) break down skills into parts; (b) describe and demonstrate clearly to-be-learned skills; (c) provide structured tasks for students to 
practice; (d) hold students accountable for their practice through teaching and feedback; and (e) provide evaluation based on students' learning.

Direct instruction has its strength and weaknesses. Scholars (Magliaro, Lockee, \& Burton, 2005) indicated that numerous studies found the DI model effective and superior to other models in learning engagement to student affect to student achievement. Rink (2002) indicates that DI became a good teaching's synonym. The DI model is the most appropriate way to teach (a) content with a hierarchical structure; (b) content focusing on basic skills; and (c) content for which learning efficiency is a focus. She went on to identify the weaknesses of the DI model. According to Rink (2002), the DI model may not be a best way to teach students when (a) the subject matter requires students' higherorder thinking skill, (b) the participant matter is not highly structured, (c) the participant matter require students' problem-solving skill. Researchers also point out that undesirable results may be produced when students assume little responsibility in the DI model, especially when the teacher uses this model to teach classes lasting longer.

\section{Information-Processing Theory}

Direct instruction relates to the information processing theory (Dell'Olio \& Donk, 2007), which aims to understand how people acquire, store, and recall information from memory (Snowman, McCown, \& Biehler, 2009).

Psychologists believe that new information is processed in three stages. They are: (a) sensory register, (b) short term store, and (c) long term store (Snowman et al., 2009). People's sense receptors can be constantly stimulated by environmental stimuli (e.g., visual, auditory, tactile), which are recorded in the sensory register. Sensory register is 
where people begin with information processing and is the first memory store. The purpose of the sensory register is to keep the information long enough so we can decide whether or not we will attend to it. Snowman et al. (2009) compared sensory register to a camera snapshot — each can last for one to three seconds before fading away. If people recognize and attend to some snapshots, they can be processed to short term memory.

When people obtain certain information, it can be processed and transferred to short term memory (second memory store), which lasts from 20 to 30 seconds. According to Miller (1956), only five to nine chunks of information can be held at one time in the short term memory. Maintenance rehearsal (e.g., mental and verbal repetition) can be used to hold information in the short term memory for immediate use (e.g., remember by mentally repeating phone number before writing them down). Dell'Olio and Donk (2007) indicated that in DI, teachers can use chunking during the cycles of content presentation, modeling, and checking for understanding.

Information can be transferred to long term memory through elaborate rehearsal. Elaborate rehearsal, which is based on organization and meaningfulness, relates new information to the ones which have already been stored in the long term memory (Snowman et al., 2009). Organization refers to organizing pieces of information into a few chunks to simplify the task, especially when one part of chunks helps us remember other chunks (as cited by Snowman, et al., 2009). The meaningfulness of information is when clear, logically organized pieces of information are presented, people then consciously relate new information to the information already stored in their long term memory (Ausubel, Novak, \& Hanesian, 1978, as cited by Snowman, et al., 2009). According to Dell'Olio and Donk (2007), people have to use the information repeatedly 
to transfer from short term memory to long term memory. Teachers in the direct instruction model provide many practice opportunities (e.g., guided, independent, distributed practice) to perform this function. Information, once stored in long term memory, can be held permanently and with unlimited capacity of storage (Snowman et al., 2009).

\section{The Dynamic System Theory}

The dynamic system theory looks at the human as a complex, biological system. This system is comprised with many subsystems which are independent but interacting (Davids et al., 2008). According to its original, Latin meaning, complex means “interwoven." Complex systems, then, are highly integrated systems composed of many parts which are affecting and interacting with each other (Davids et al., 2008). Theses interactions at the micro-component level (among each part) are random and inclined to have much disorder within the whole system (e.g., turbulence makes flow of water molecules become unpredictable) (Davids et al., 2008). However, at the macroscopic (large-scale) level, ordered patterns of behavior were surprisingly witnessed (Davids et al., 2008).

Newell (1986) believes that constraints are boundaries that limit the motion of the micro-component of a system. He identified three categories of constraints: organismic, environmental, and task. Organismic constraints include structural constraints (e.g., height, weight, size) and functional constraints (e.g., synaptic connection development). The distinction between structural and functional constraints, although not qualitative, is that structural constraints are relatively time independent, while functional constraints are 
relatively time dependent. Environmental constraints are time independent and refer to those constraints that are outside of the organism (e.g., light, gravity, temperature). Task constraints refer to the specific constraints for the activity goal and include three categories: (a) task goals, (b) rules constraining response dynamics, and (c) implements or machines constraining response dynamics.

These three categories of constraints are interacting, and as the interaction of constraints occurs on the neuromuscular system, different states of coordination will emerge and be refined with practice and experience (Davids et al., 2008). For example, the type of activity the teacher chooses to teach while asking students to practice gymnastics tumbling is dependent on the student's own characteristics (e.g., height, weight), previous gymnastics training experience, current status (e.g., injured or not), available equipment (e.g., gymnastics mat, indoor gym floor, outside playground), and the student's practicing goals (e.g., normal speed, demonstrating slowly to other students). Study from nonlinear systems indicates that constraints are temporary and can be changed (decay or strengthen) according to different timescales (Guerin \& Kunkle, 2004). For example, stretching practice can decay the ligament constraints and make body become more flexible. However, the constraints are strengthened for ligament-injured people. Strengthening or decaying the constraints results in increasing or decreasing the entropy of the system. Davids et al. (2008) believes that it is important to consider this point for skill acquisition. They also indicate that teachers should view constraints on each individual student as dynamic, interacting, and changing over time following influences (e.g., experience, getting older, more skillful). 
Motor skills can be learned at explicit and implicit levels. Explicit learning is learning through effort, verbal instruction, and consciousness (Shea, Wulf, Whitacre, \& Park, 2001). Faldo (1986) made a long list of do's and don'ts for golf putting strokes and he indicated that too much thought has a negative impact on the performance. Masters and his colleagues (2002) concluded based on previous research that instructions may increase action awareness, which would have negative effect on performance during practice and under psychological conditions (e.g., anxiety, stressfulness).

Implicit learning is learning under the environment free of conscious effort or verbal instruction (Shea et al., 2001). Liao and Masters (2001) conducted two experiments in an effort to examine the effects of learning by analogy on implicit motor learning. The first experiment asked novice table tennis participants to hit a topspin forehand explicitly, implicitly, or by analogy. Participants in the explicit learning group were provided twelve basic techniques to hit topspin. Participants in the analogy group were taught to draw a right-angled triangle with the paddle and bring the paddle up along the hypotenuse of the triangle to hit the ball. Participants in the implicit learning group were taught to repeat number sequences. The results showed that the analogy and implicit learning groups combined exhibited fewer explicit rules than the explicit learning group. The performance of the explicit learning group was more detrimental when a concurrent secondary task was added. In the second experiment, performance of the explicit learning group was negatively impacted by both stress and thought suppression intervention. These emotional effects did not affect the performance of the analogy learning group. The author concluded that analogy learning would be an effective method for implicit teaching in sport. 
Research on focus of attention has been conducted to examine the effects of both internal and external focus of attentions (Wulf, Hoess, \& Prinz, 1998; Wulf, Lauterbach, \& Toole, 1999; Wulf, McNevin, \& Shea, 2001; Zachry, Wulf, Mercer, \& Bezodis, 2005). Most of the research supported the effectiveness of external focus of attention to the skill learning acquisition. Wulf et al. (1998) conducted two experiments to examine the effect of external versus internal focus of attention. In the first experiment, the participants were required to perform slalom-type movements on a ski-simulator. One group of participants was required to focus their attention on their feet (internal focus), while the other group of participants focused on the wheels of the platform located under the feet (external focus). No focus of attention was given to the control group. All participants practiced the task for two consecutive days and performed the third day for a retention test. The results showed that the groups that received external focus attention improved their learning, while the internal focus learning group and the control group had limited improvement. The second experiment aimed to compare the effects of external with internal focus attention using the task of balancing on a stabilometer. One group of participants focused their attention on two markers on the platform of the stabilometer (external focus), while the other group of participants focused on their feet (internal focus). Results showed that the external focus attention group obtained more learning compared with the internal focus attention group.

Wulf et al. (1999) employed participants with no golf experience to practice pitch shots. One group of participants were required to focus on the arm swing (internal focus) while the other group focused on the club swing (external focus). The participants practiced 80 practice trials for one day. The participants also practiced 30 practice trials 
for retention test one day later. The results found that the external focus attention condition had more positive effects on the performance during practice and retention tests. Wulf et al. (2001) used a stabilometer to examine the effect of internal versus external focus of attention and found that the external focus group exhibited fewer balance errors compared with internal focus group. They also found that external focus group demonstrated a higher degree of automaticity and less conscious interference when performing the balance task. Zachry et al. (2005) employed participants to perform basketball free throws. One group of participants focused on the wrist motion (internal focus) and the other group focused on the basket (external focus). The results found that the participants have better free throw accuracy under the external focus condition compared with under the internal focus condition.

\section{Ecological Task Analysis}

The definition of task analysis was the process of identifying the skill component and ordering them in an easy to hard sequence (Dunn \& Fait, 1989; Sherrill, 1986; Wehman \& Schleien, 1981). Its purpose was to help instructors to assess skills, provide lesson goals, and teach children with different needs and function levels individually (Davis \& Burton, 1991). Davis and Burton (1991), in their classic study, listed several categories of traditional task analysis which include information processing (e.g., Thorndike's "laws of effects"); rational, prerequisite, and anatomical task analysis (e.g., attempt to specify procedure used in task performance); and developmental task analysis (e.g., when teaching difficult task, you need to break task into parts, each part has task goals). There are, however, many problems within traditional task analysis. Those problems include: (a) lack of clear definition and procedure, (b) lack of research support, 
and (c) absence of performer in the task analysis. Thus, ecological task analysis has been provided to (a) understand the dynamics of student movement behavior, (b) develop teaching strategies through cues, and (c) provide success to students in task performance.

The concept of affordances is the foundation of Gibson's ecological approach to perception (Gibson, 1966). He defined the affordance as the opportunity for action that a specific environment offers or "affords" a particular person. Gibson indicated that people should perceive the environment based on its functional utility and that the functional based information should guide their action. Based on this theory, four concepts of task analysis emerged: (a) actions are relations instead of parts, (b) tasks need to be categorized by function and intention instead of mechanism, (c) invariant features of a task may be defined in terms of essential variables, while variations within a task may be defined in terms of non-essential variables, and (d) there should be direct links among the task goal, the performer constraints, and the environment (Davis \& Burton, 1991).

Critical concept two indicates that tasks need to be categorized by function and intention instead of mechanism. Davis and Burton (1991) identified five functional task categories. They are: (a) Locomotion (e.g., craw or walk), (b) Locomotion on object (e.g., propel bicycle or boat), (c) Propulsion (e.g., carry or lift), (d) Reception (e.g., catch or grasp), and (e) Orientation (e.g., bend or manipulate). The authors indicated that the functional task, performer's constraining features, and the environment together defined the skills that can be used to perform the task. Critical concept three indicates that invariant features of a task may be defined in terms of essential variables, while variations within a task may be defined in terms of non-essential variables. In ecological task analysis, the goal of a task is invariant. Shapiro and Schmidt (1982) believed that 
essential variables include relative timing and relative force. Non-essential variables refer to the parameterization of the function (Davis, 1986; Kugler, Kelso, \& Turvey, 1980, 1982; Newell, 1986). Specifically, “dimension” was used to describe non-essential variables in terms of its physics and mathematics definition in ecological task analysis. It was found (Bingham, Schmidt, \& Rosenblum, 1989) that the weights of the objects chosen increased according to the size increase of the participant when the participants were required to throw the objects to a maximum distance. Critical concept four indicates that there should be direct links among the task goal, the performer constraints, and the environment. In ecological task analysis, we use "performer-scaled" or "intrinsic" units (Kugler, 1986; Kugler \& Turvey, 1987; Warren, 1984) to link task and environment to performer. Boundary conditions of a task also can be established by using performerscaled dimension to link task, performer, and environment together. The example of using a performer-scaled unit is to select a dimension of interest (e.g., diameter of the ball) for a certain task (e.g., one-hand dribbling), indicate performer metric (e.g., hand width) expressed in the same unit as dimension of interest, and dividing the dimension value by the performer metric.

Davis and Burton (1991) indicated that ecological task analysis is designed for assessment and instruction of skill performance. They provided four steps to carry out an ecological task analysis. The first step is to identify task goals or functions that need to be accomplished. The instructor should establish the environment and use explanation and demonstration to help students understand the goal of the task and criteria before they choose certain skills for the task goal. The second step is to provide opportunity for students to choose the skill and movement form (e.g., throwing or striking a softball) they 
can use for certain functional tasks (e.g., propelling an object). The instructor can measure the student's skill qualitatively (the throw did or did not reach the target accurately) or quantitatively (the accuracy relative to the distance). The third step is to identify task dimension and performer variables. The instructor should teach by: (a) emphasizing the task goal and encourage students to focus on the environmental information pertaining to that goal, (b) providing positive feedback when the students achieve the goal successfully, and (c) providing challenges to make the task more difficult after they achieve the goal. The fourth step is to provide direct instruction to the students using traditional teaching methods (e.g., demonstration).

Balan and Davis (1993) discussed using ETA as an approach to teaching physical education. They believed the behavioral objectives and the measurable and observable of the goals are identified (the first step) and skills are chosen. They highlighted setting up physical and social environments and allowing students to choose the skill and form. Examples of setting up the environment are (a) asking the students to go from one place to another or change postural positions after reasons are provided to locomote or move. Attractive objects and students at the different places of the gym allow them to choose ways to retrieve the objects; (b) adding obstacles, and asking students to go over or under them can be challenging; (c) using students' imaginative skills for chasing games can change their movement form. Several objects in setting up the environment are (a) communicating the goal of the task, (b) inviting students to participate, (c) giving students an opportunity to make a choice, and (d) providing enough equipment for the tasks change. They stressed that the instructors should first list implement, equipment, and objects for the identified goals. Traditional choices and options used to change the 
task for individualization and challenge could be used. The environment should also be set up in such a way that any one specific skill is emphasized and observe if the students choose that skill to accomplish the goal of the task. Students also can help to set up the environment. Allowing students to choose skill, movement form, and equipment (the second step) is effective in teaching because it can provide students with self-motivation, enhance their decision-making and self-monitoring ability, encourage them to discover the most effective form individually, and give them control over the environment to gain the feeling of belonging. Manipulation (the third step) is to change the dimensions of the task, environment, and student characteristics for general task categories (locomotion on land/in water, object manipulation, object propulsion/reception, postural maintenance and orientation) to provide success. The rule of success criterion was defined as 75 percent (make a goal three out of four times). Manipulation should be implemented if a student's success is below 75 percent criteria. The teacher's main job is to observe and record the students' choices except for restating or changing the goal of the task. This step is student-centered, exciting, social, and fun. Making tasks more difficult to challenge students is very important because it can improve performance.

Balan and Davis (1993) indicated that challenges can be provided through changing dimensions. The first way to provide challenge is to change the goal and/or task conditions without varying the generally preferred skill or the task goal (e.g., ask students to hit the target four out of five times if the goal is to hit a target using the skill of throwing overhead). The other way to challenge students is to vary the generally preferred skill without changing the goal or conditions of the task (e.g., using different skills such as kicking or bouncing for the goal of hitting the target). Balan and Davis 
(1993) indicated that instructors should implement challenges at the highest point of the involvement before the students get bored. They also provided the following guidelines for challenge introduction and assessment: (a) avoid threatening manner when presenting challenge questions such as "show me how many times you can pass the ball to your partner without dropping the ball," (b) tell students in advance that challenges will probably affect their success of achieving task goal (the instructors should encourage the students to keep trying if they fail), and (c) make sure that the most recent experience is successful before changing the activity. Providing instruction is still be put in the fourth or final step of ETA model instruction in the Balan and Davis (1993) study. Balan and Davis (1993) argued instruction can take many traditional forms (e.g., direct instruction) and should be provided after the students understand the goal of the task, make a choice of skill to achieve that goal, or experience successes and challenges.

Burton and Davis (1996) discussed using intrinsic measures in practice. They indicated that intrinsic or performer-scaled measures can directly link task goals and the constraints of performer and environment. This measure can match certain task parameters with performers to make a task/performer ratio. They also believed intrinsic measures are dimensional numbers. Burton, Greer, \& Wiese-Bjornstal (1993) discussed using dimensionless or intrinsic measures to examine the ball diameter/hand width ratio. They found that when ball diameter just exceeds hand width, people change from one- to two-hand consistently. Rutter (1987) examined the intrinsic measure of finger span, index to thumb, divided by digits against sphere diameter. It has been found that although children and adults have different absolute measures, they were similar on the intrinsic 
measures. That is when the object was in the relative same size, children and adults used similar number of fingers to grasp the object.

\section{Behavior Analysis in Sports Performance}

Research in behavior analysis has been conducted in several sports. These include football (Allison \& Ayllon, 1980; Smith \& Ward, 2006; Ward \& Carnes, 2002), basketball (Kladopoulos \& McComas, 2001; Romanowich et al., 2007; Vollmer \& Bourret, 2000), gymnastics (Allison \& Ayllon, 1980; Boyer et al., 2009), tennis (Allison \& Ayllon, 1980), inline roller speed skaters (Anderson \& Kirkpatrick, 2002), soccer (Brobst \& Ward, 2002), and rugby (Mellalieu et al., 2006).

Many interventions in previous studies included verbal feedback, public posting, and goal setting. Brobst and Ward (2002) examined the effects of an intervention package of public posting, goal setting, and oral feedback. The study evaluated how the intervention package affected (a) improvement in practice, (b) improvement extension to game play, and (c) the acceptability of this intervention to coaches and players. Participants were three female players, ages 15 to 17 years, from a high school soccer team. Dependent variables were: movement with the ball (player receives the ball and dribbles for at least five seconds without losing the ball), movement during restarts (when the game restarts and ball is thrown in, players move to an open space to try to receive the ball), and movement after the player passed the ball (player passes the ball and moves to a supporting position). The study used a multiple baseline design across these three behaviors. The coaches and players also were required to complete a questionnaire to examine the social validity. The results showed an effective intervention for performance 
improvement during practice. The improvement, however, did not extend to the game play when the intervention was removed, which differed from previous studies.

Smith and Ward (2006) compared the effects of (a) goal setting plus verbal feedback, (b) public posting plus verbal feedback, and (c) goal setting plus public posting plus verbal feedback on the performance of football players. The study also measured the extent to which the generality of improvement was to the game setting. Three wide receivers who were rated as poor during demonstrations of wide receiver skills participated in the study. The dependent variables were (a) the correct blocking percentage, (b) the correct routes run percentage, and (c) the percentage of correct releases from the line of scrimmage. An ABACABC multi-treatment withdrawal design was used in the study to examine the effectiveness of these three interventions. The results show that although each treatment was better than the baseline, the treatment of goal-setting, plus public posting, plus verbal feedback was more effective than the other two treatments. The results also indicate improvement generalization from practice settings to game settings. The questionnaire investigation shows that coaches and players preferred the combined intervention.

Anderson and Kirkpatrick (2002) investigated the effects of verbal feedback and differential positive reinforcement on the performance of competitive inline roller speed skating. Four skaters (one female, three male), ages 12 to 16 years, participated in the study. The dependent variable was the percentage of correct demonstration of relay tag. Two sessions were conducted in the study. The first session included a baseline procedure followed by an intervention procedure for three skaters. A multiple baseline design across participants was used in this phase. The second session was conducted six 
months later with baseline and intervention procedures implemented concurrently for the same three skaters. The study experimented on the fourth skater to replicate the initial findings of those three participants. A reversal design was used in this phase. The results showed that the intervention in the first session was effective to increase the number of correct tags for all three skaters. However, this improvement did not maintain in the second baseline. The intervention in the second phase (after the second baseline) was more variable for the three participants. The study replicated the original findings in the fourth participant. The authors believed the treatment package was effective at least in the first implementation to improve inline skater performance.

Some studies examined the specific effect of goal setting. Ward and Carnes (2002) experimented on the intervention of self-set goals and public posting on the performance of football players. Five collegiate football players, ages 19 to 21 years, who were rated as poor demonstrators of the target skills participated in the study. The correct demonstration percentage of "reads," "drops," and "tackles" were identified as three dependent variables. A multiple baseline design across these three skills was used to measure the effectiveness of the intervention. The results showed that the correct percentage of the target skills increased in the practice and game settings after the intervention (public posting plus self-set goals) was implemented. Mellalieu and Hanton (2006) replicated and extended the effects of goal-setting on the performance of competitive rugby. Five male rugby starting players, ages 21 to 24 years, participated in the study. The dependent variables were number of carries, number of tackles (made or missed), successful kicks, and number of turnovers won. The study covered 20 games, including the first 10 matches as the baseline, and the second 10 matches as the 
intervention period. The treatment was implemented at midseason. Thus, the study used a non-experimental A-B design. The results indicated that the treatment was effective in improving skills performance.

The effects of behavioral coaching in the skills development in football, gymnastics, and tennis were investigated by Allison and Ayllon (1980). The intervention in the study was a behavioral package which included the five steps of (a) executing the play, (b) judging correct execution, (c) describing the incorrect position, (d) modeling the correct position, and (e) imitating the correct position.(Kladopoulos \& McComas, 2001) In the football part of the study, participants were five males, aged 11 and 12. The dependent variable was correct percentage of blocking execution. The study used a multiple baseline design across four participants and a reversal $\mathrm{ABAB}$ design with the fifth participant. In the gymnastics part of the study, six participants, ages 13 and 14 years, from a high school gymnastics team was chosen. The dependent variables were correct percentage execution trials of backward walkovers, front handsprings, and reverse kips. The study used a combination multiple baseline design across participants and skills with reversal designs on each behavior for each participant. In the tennis part of the study, 12 participants from a large urban university, ages 18 to 35 years, participated in the study. The dependent variables were correct demonstration percentage of forehand, backhand, and serve stroke. Multiple baseline designs across behaviors and individuals were implemented in the study. The findings showed that this five step coaching was effective in all three sports. In each intervention of the three sports, the gains were up to 10 times the baseline performance. 
Form training (Kladopoulos \& McComas, 2001) and video modeling (Boyer et al., 2009) were also used as intervention in the recent study. In the form training study, the authors investigated the effects of form training on the performance of basketball foulshooting. Three women's college basketball team members aged 19 to 20 years old participated in the study. The dependent variables are the shots percentage for each 10shot session and the correct form used for the shots percentages made for each session. A multiple baseline design across participants was implemented in the study. The results indicated that the proper form training and feedback was effective in increasing shots made percentage and in proper form. The simultaneous increase in shots made percentage and shots made percentage with proper form showed that the proper form is related to foul shooting accuracy. The video modeling study measured the effects of video modeling by experts plus video feedback on the performance of three gymnastics skills. Participants were four female competitive gymnasts, ages 7 to 10 years old. The dependent variables were giant, kip cast, and clear hip circle. A multiple baseline design across behaviors was used in the study. The results indicated that the intervention can (a) quickly improve the skill performance compared to the baseline, and (b) reduce the number of practice times required to improve skill performance. The follow-up measures showed that the skill performances were maintained by these three gymnasts, even though the intervention was withdrawn. Finally, social validity questionnaires indicated the acceptability to the coaches and gymnasts.

Vollmer and Bourret (2000) used matching equations to examine the allocation of two- and three-point shots by male and female basketball players. The results showed that the matching equation predicted the overall distribution of two-and three-point shots. 
While game-by-game distribution of shots was unstable, the three-point cumulative proportion shots were predicted nicely for both male and female basketball players on a player-by-player basis. Romanowich et al. (2007) extended the matching law research by examining if the two-and three-point shots proportion would match the proportional reinforcement rates of those shots when the range of three-point shots changed. Results partially confirmed the matching law predictions. Decreasing the range of three-point line increased the mean rate of shots made, while increase the three-point line did not decrease the mean rate of shots made. 


\section{CHAPTER THREE}

\section{Method}

The purpose of the study was to compare the effectiveness of Direct Instruction (DI) with the combination of direct instruction and environmental design instruction (DI+EDI) on both simple and difficult gymnastics skills. Two experiments were conducted in the study. One skill was chosen in each experiment in which two teaching methods had been implemented alternatively.

In the first experiment, the skill of running tuck jump on the springboard was chosen as the simple skill. The two teaching methods had been implemented on this skill in an effort to determine which method has the more positive effect on the process (form) and the product (height) of the skill. A good form of running tuck jump should have a straight back and tucked body while jumping at the highest point, and a high jump. The form of the running tuck jump on the springboard was analyzed by measuring participants' hip angle (the angle between the line drawn from the knee to the hip points and the line drawn from shoulder to hip points) and back angle (the angle between the line drawn from participant's shoulder to hip points and the vertical line drawn through participant's hip) while the participant reached the peak point in the air. The height of the running tuck jump on the springboard was analyzed by measuring the distance between the participant's toe points to the floor while the participant jumped at the highest point.

The skill of circles on the mushroom was chosen as the difficult skill in the second experiment. The two teaching methods were alternatively implemented on this skill in an effort to determine which method has more positive effect on the form of the 
circles on the mushroom. A good form of circles on the mushroom is defined as one which fully extends the body. To analyze the form of circles on the mushroom, researchers measured the participants' torso angle (the angle between the torso and the lower body) and arm angle (the angle between the torso and the arm) while they were performing circles on the mushroom.

The hypothesis in the first experiment was that DI+EDI would have a more positive effect on the process and the product of the running tuck jump on the springboard compared with DI. Specifically, DI+EDI could help decrease the hip angle (the angle between the line drawn from the knee to the hip points and the line drawn from shoulder to hip points) and back angle (the angle between the line drawn from participant's shoulder to hip points and the vertical line drawn through participant's hip) while jumping at the highest point. It was also hypothesized that DI+EDI would also increase the height of the running tuck jump on the springboard.

The hypothesis in the second experiment was that DI+EDI would have less positive effect on the form of mushroom circles compared with DI. Specifically, it was predicted that DI+EDI would not help increase the torso angle (the angle between the torso and the lower body) and arm angle (the angle between the torso and the arm) while performing circles on the mushroom. Researchers will discuss the experiments in the following sections: (1) participants, (2) dependent variables, (3) independent variable levels, (4) research design, (5) procedure, and (6) data analysis.

\section{Participants}


Four boys participated in the first experiment (running tuck jump on the springboard). All of them were training members of WVGTC and had 2 years of gymnastics training experiences. They had practiced the running tuck jump on the springboard for one year and their form had been identified by the coach as having some weakness. Their ages were from six to eight.

Four boys who had more than three years of gymnastics training experience participated in the second experiment (mushroom circles). All the participants were training members of the WVGTC. Their ages were from 11 to 13. All of the participants had practiced mushroom circles for two years. Their form of mushroom circles had been identified by the coach as having some weaknesses. All the participants were able to do multiple circles on the mushroom, but errors in form were present in their performance.

The parents of all the participants signed a consent form indicating the willingness of letting their children participate in the study. Assent forms were signed by the participants to indicate their willingness to participate in the study. Approval was obtained from the Institutional Review Board (IRB).

\section{Dependent Variables}

Dependent variables are target behaviors in single participant research design. In the experiments, movement form at the peak point and height while participants were performing the running tuck jump and movement form while they were performing mushroom circles were identified as the dependent variables.

Specifically, in the experiment of a running tuck jump on the springboard, researchers choose (a) performance form while the body was at the peak point and (b) the 
body height as dependent variables. Two angles were identified to be related with performance form while the body was at the peak point. The first angle was the participants' hip angle (the angle between the line drawn from the knee to the hip points and the line drawn from shoulder to hip points). This angle represents the tightness with which the participants can bring their knees to their chest. The smaller the angle is, the closer the participant brings his or her knees to the chest. The second angle was the participants' back angle (the angle between the line drawn from participant's shoulder to hip points and the vertical line drawn through participant's hip). This angle represents the uprightness the participant's torso would be while at the peak point. The smaller this angle is, the closer the torso would be towards uprightness. The other dependent variable in the experiment of running tuck jump was the performance height while the body was at the peak point. The performance height was calculated by measuring the distance between the participant's toe points to the floor. The performance height represents how high the tuck jump would be. The higher the tuck jump, the better.

In the experiment of mushroom circles, the good form of the skill is fully extending the body while performing circles on the mushroom. Two angles of the body were identified to be related to body extension while the participants' circles on the mushroom were at the front of the mushroom. The first one was the torso angle (the angle between the torso and the lower body) in which the closer the angle towards 180 degrees, the better the form would be. The second one was the arm angle (the angle between the torso and the arm) in which the larger the angle is, the better the form would be.

\section{Independent Variable Levels}


The independent variable is instructional condition (Kazdin, 1982). There were two levels of the independent variable in both experiments. The first level was DI. The second level was the combination of DI and EDI (DI+EDI).

Direct instruction. During DI, the teacher exhibited three behaviors. They were: (1) demonstrating the skill, (2) providing skill's cues, and (3) giving feedback after the participant finished each set of the skill. Specifically, in the experiment of running tuck jump (Experiment 1), DI consisted of (1) demonstrating the running tuck jump on the springboard for one set, (2) providing the cues of the running tuck jump on the springboard for one set, and (3) providing feedback each time after the participant finished one set of the practice and landed on the mat. The cues of running tuck jump include circling arms while stepping on the springboard, bringing knees close towards chest, keeping straight back while jumping in the air, and jump as high as they can.

In the experiment of mushroom circles, DI was comprised of (1) demonstrating five circles in a row (one set of the practice) on the mushroom for each participant for one time, (2) providing cues for the mushroom circles for each participant for one time, and (3) providing feedback each time after the participant finished one set of the practice. The cue of mushroom circles is fully extending body while performing circles on the mushroom.

Combination of DI and EDI (DI+EDI). In the experiment of running tuck jump (Experiment 1), an adjustable hurdle was used for EDI. The adjustable hurdle was placed in front of the springboard at a point where a vertical line was drawn from an Elite gymnast's hip point at the peak point when he performed the demonstration. The hurdle 
was adjustable (could be raised or lowered). The participants' peak body height was measured by measuring the distance between the participant's toe points to the floor while jumping at the highest point. Each participant was taught by DI first. The height of the hurdle was set up according to the participants' requirements and was at least three centimeters higher than the previous mean body height for Adam, Harry, and Mark. It was at least one centimeter higher (with one exception session) than the previous mean body height for Tim when they were taught by DI.

In the experiment of mushroom circles (Experiment 2), a 90 degree bent plastic tube was inserted with one side into a hitting tee's ball holder. A string was hung from the top of tube. The string could be raised or lowered. The tee could be moved closer or farther away from the mushroom. The hitting tee and the string were adjusted for each participant to a point where each participant's toes can almost touch the string while their circles' position was in front of the mushroom. The position of the tee and the string will be recorded and saved for EDI set up.

In the experiment of running tuck jump, the coach demonstrated the running tuck jump on the springboard for one set, and provided cues of the skill. The coach then set up the EDI and provided feedback each time after the participant finished each set of the practice and landed on the mat. Each participant's five sets of running tuck jump were video recorded and analyzed after each practicing day.

In the experiment of mushroom circles, the coach demonstrated five circles in a row (one set) on the mushroom, and provided cues of the mushroom circles for each participant for one time. The coach then set up the EDI and provided feedback each time 
after the participant finished one set of the practice. Each participant's three sets of five circles on the mushroom were video recorded and analyzed after each practicing day.

\section{Research Design}

Both experiments used an alternating treatments single-case research design. The term alternating treatment design was proposed by Barlow and Hayes (1979) and is an experimentally sound method for comparing two or more treatments' effects (Cooper, Heron, \& Heward, 2007).

The characteristics of the alternating treatments design include rapid alternations of two or more treatments (independent variable levels) and the measurements of the effects on the target behaviors (Cooper et al., 2007). In the current study, two treatments (DI and DI+EDI) were alternated across daily sessions with one treatment in effect for each day. Both experiments were taught by DI for the first day, and the following each day's treatment was determined by a coin flip.

\section{Procedure}

Approval was obtained from WVGTC to use all the necessary equipment in the gym. West Virginia University's Institutional Review Board (IRB) approval was obtained in order to conduct the experiments. Consent forms were signed by the parents of the participants for the willingness of letting their children to participant in this study. Assent forms were also signed by each participant to in order to show the willingness to participate in the study. 
The experiments were conducted in the summer training session. All the participants practiced four times a week with each experiment lasted approximately ten minutes. Two practicing days were in the morning and the other two practicing days were in the afternoon. Experiments were conducted at each practicing day for about 25 days. Each practicing day consisted of (1) warm-up, (2) core practice, and (3) conditioning practice. Warming-up lasted for 30 minutes and was comprised of five minutes of cardiovascular activity followed by 25 minutes of stretching. Core practice lasted for three hours, and each hour was spent on the gymnastics event in the order of floor, pommel horse (mushroom), still rings, parallel bars, vault (running jump on the springboard), and high bar. They practiced on one day the first three events (floor, pommel horse, and still rings) and on the second day the last three events (parallel bars, vault, and high bar).

The experiments were conducted on each practicing day after the warming-up activity. Experiment 1 (running tuck jump on the springboard) was conducted first followed by Experiment 2 (mushroom circles) for each experimental day. After warmingup, the participants were led to the running tuck jump station first for Experiment 1 individually. The tuck jump station consisted of a springboard and a mat put in front of the springboard. There were five springs inside the springboard. The springboard and the mat were put on the standard gymnastics spring floor. The position of the mat and the springboard were marked to make sure the tuck jump station was at the same place across Experiment 1 . The participant first practiced the running tuck jump under DI followed by the teaching method decided by flipping a coin before the experiment day by the author. The participants were asked to run a distance of 25 feet, perform a tuck jump on the 
springboard, and land on the mat for five sets under DI with all five sets being videotaped and analyzed after each practicing day. After finishing all five sets (one set means performing a running tuck jump on the springboard and landing on the mat for one time) of running tuck jumps on the springboard, the participant was sent to normal core practice and switched out with another participant until all four participants finished their five sets of practice.

After the Experiment 1, the participants were guided to the mushroom circles station as a group. The investigator acted as a coach to teach them circles on the mushroom under DI first followed by the same teaching method as the Experiment 1 . The participants were required to practice five circles in a row on the mushroom in order to finish one set. The participant practiced mushroom circles for three sets under certain teaching method with all sets being video recorded for data analysis. After finishing the three sets of mushroom circles, the participant was sent to normal core practice and switched to another participant until all four participants finished the experiment. The videotape was analyzed after each practicing day to keep track of the performance form.

\section{Data Analysis}

Videos for both experiments were analyzed using Dartfish software. The Dartfish program was used to analyze the two body angles and body height in the experiment of running tuck jump (Experiment 1) and the two body angles in the experiment of mushroom circles (Experiment 2). The participants practiced five sets for the experiment of running tuck jump and three sets for the experiment of mushroom circles each day. 
The five sets of running tuck jump and three sets of mushroom circles were videotaped each day and analyzed using Dartfish software.

In Experiment 1, running tuck jumps on the springboard were video recorded and analyzed using Dartfish, specifically measuring participants' (1) hip angle (the angle between the line drawn from the knee to the hip points and the line drawn from shoulder to hip points), (2) back angle (the angle between the line drawn from participant's shoulder to hip points and the vertical line drawn through participant's hip), and (3) jump height (the distance between the participant's toe points to the floor while the body is at the peak point).

In Experiment 2, circles on the mushroom were videotaped and analyzed using Dartfish, specifically measuring participants' (1) torso angle (the angle between the torso and the lower body), and (2) arm angle (the angle between the torso and the arm).

A second analyzer randomly selected $30 \%$ of the experimental data to analyze for inter-rater reliability. The selected data included five practicing days including both experiments taught by both teaching methods. The second observer analyzed the two angles and body height for Experiment 1 and the two angles for Experiment 2 individually. Specifically, the second analyzer analyzed each participant's back angle, hip angle, and jump height for each set of the Experiment 1 with a total of five sets analyzed in each session for each participant. The mean of five sets of inter-observer agreement was calculated for each participant's dependent variables for both analyzers. Interobserver agreement percentage was calculated by dividing the lower degrees/height by higher degrees/height and then multiplying by 100. Inter-observer reliability was between 
$77 \%$ to $98 \%$ for back angle, $89 \%$ to $99 \%$ for hip angle, and $93 \%$ to $99 \%$ for jump height. The second analyzer also analyzed each participant's torso angle and arm angle for each mushroom circle with a total of 15 circles (three sets) analyzed in each session for each participant. The means of 15 torso angle and 15 arm angle (three sets) were calculated for each participant in each session for both analyzers. Inter-observer agreement percentage was calculated by dividing the lower degrees by higher degrees and then multiplying by 100. Inter-observer agreement was between $97 \%$ to $99 \%$ for torso angle and $88 \%$ to $99 \%$ for arm angle.

The study analyzed the effectiveness of the two interventions (DI, and DI+EDI) using visual inspection. According to Kazdin (1982), visual inspection means reaching a judgment about the reliability or consistency of intervention effects through visually examining the graphed data. Visual inspection relies especially on the data pertaining to the magnitude of the changes across phases and the rate of these changes. Changes in means or level are related to magnitude. Changes in trend and variability are the two characteristics of related to rate (Kazdin, 1982).

In the visual analysis of behavioral data, level is examined within a condition in terms of the absolute value (e.g., mean) on the y-axis scale. The mean level of a series of behavioral measures within a certain condition can be illustrated graphically by mean level line and level is determined by mean lines and compared from phase to phase (Cooper et al., 2007). Changes in trend refer to the tendency for the data to show systematic increases or decreases over time. Trend changes allow people to observe the direction of behavior changes within a phase (Kazdin, 1982). Changes in variability refer to the fluctuation of a participant's performance over a certain time. Standard deviation of 
all data points for a certain phase is calculated to represent changes in variability. The greater the variability in the data, the more difficult it is to draw conclusions about the effects of the intervention (Kazdin, 1982).

\section{CHAPTER FOUR}

\section{Results}

\section{Experiment 1 (Running Tuck Jump)}

In the skill of a running tuck jump, three dependent variables were analyzed: (1) the angle between the line drawn from the knee to the hip points and the line drawn from shoulder to the hip points (hip angle); (2) the angle between the line drawn from participant's shoulder to hip points to the vertical line drawn through the participant's hip (back angle); and (3) the distance between the participant's toe points to the floor while jumping at the highest point (jump height).

All six DI sessions has been checked for the fidelity of teacher's behavior. Because of the fact that all participants have already learned the skill of running tuck jump and watched the teachers' demonstration for multiple times before, the teacher in the current study did not demonstrate the skill for each session day. The results indicated that the teacher demonstrated the skill of running tuck jump in two DI session days (the first and second DI session days). The teacher provided cues before letting the participants perform the skill for all six DI session days. The teacher also provided feedback to each participant following each set of their performance for all six DI session days. 


\section{Hip angle.}

Participant 1 (Adam). Participant 1 will be referred to as "Adam" (fictitious name). Figure 1 displays the results for the hip angle in Adam's tuck jump. The mean hip angle under direct instruction (DI) is 77.9 degrees. The mean hip angle was greater $(81.1$ degrees) when under DI and environmental design instruction (DI+EDI). Adam's hip angle trend in DI was negligible (trend=0.138). His hip angle in DI+EDI had a downward trend (trend=-1.45) as seen in Figure 1. The variability of Adam's hip angle in DI was $\mathrm{SD}=14.5$. The variability of his hip angle in $\mathrm{DI}+\mathrm{EDI}$ was $\mathrm{SD}=11.4$. Thus, DI appeared to produce more variability in Adam's hip angle.

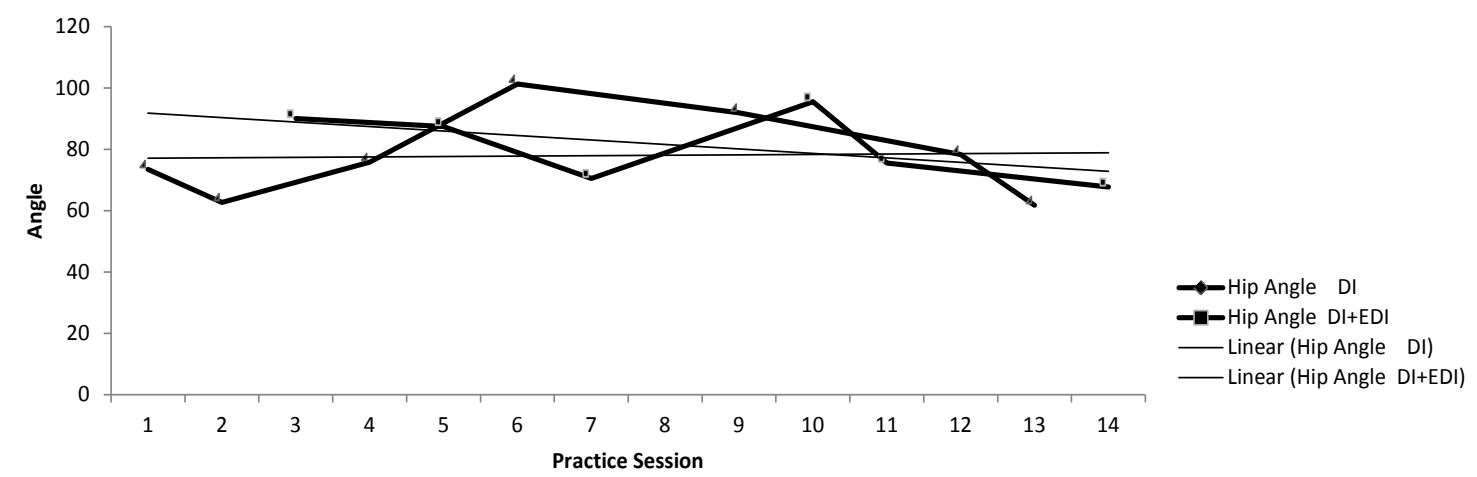

Figure 1. Adam's hip angle for running tuck jump.

Participant 2 (Harry). Participant 2 will be referred to as "Harry" (fictitious name). Figure 2 displays the results of Harry's hip angle for running tuck jump. Harry's mean hip angle in DI was 65.9 degrees. His mean hip angle was less at 49.4 degrees in DI+EDI. Harry's hip angle in DI had a negligible upward trend (trend=0.5). A more upward trend was observed in his hip angle in DI+EDI (trend=1.1). The variability of Harry's hip angle 
in $\mathrm{DI}$ was $\mathrm{SD}=8.6$ degrees. The variability of his hip angle in $\mathrm{DI}+\mathrm{EDI}$ was $\mathrm{SD}=4.7$ degrees. Thus, DI+EDI appeared to reduce performance variability.

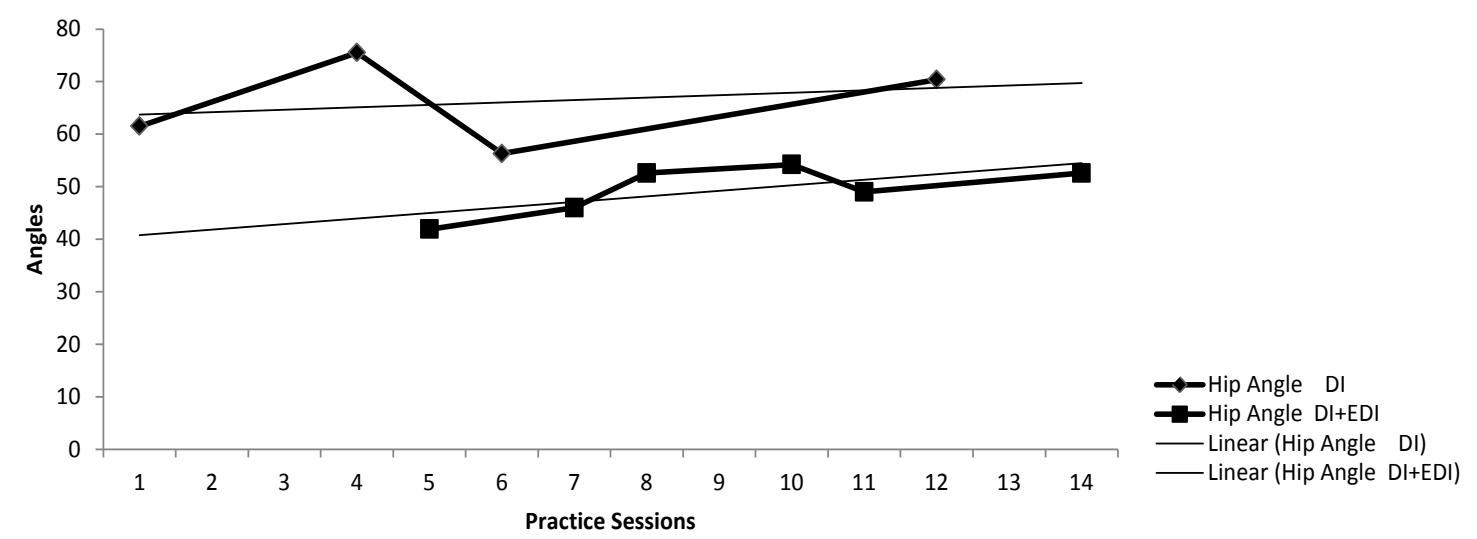

Figure 2. Harry’s hip angle for running tuck jump.

Participant 3 (Mark). Participant 3 will be referred to as "Mark" (fictitious name).

Figure 3 displays the results of Mark's hip angle for running tuck jump. Mark's mean hip angle in DI was 55.5 degrees. His mean hip angle in DI+EDI was less at 45.6 degrees. Mark's hip angle in both DI and DI+EDI had almost no trends (trend=-0.13 for DI, trend $=0.17$ for DI+EDI). The variability of Mark's hip angle in DI was SD=11.3 degrees. The variability of his hip angle in $\mathrm{DI}+\mathrm{EDI}$ was $\mathrm{SD}=7.1$ degrees. Thus, $\mathrm{DI}+\mathrm{EDI}$ appeared to have produced lower variability in hip angle. 


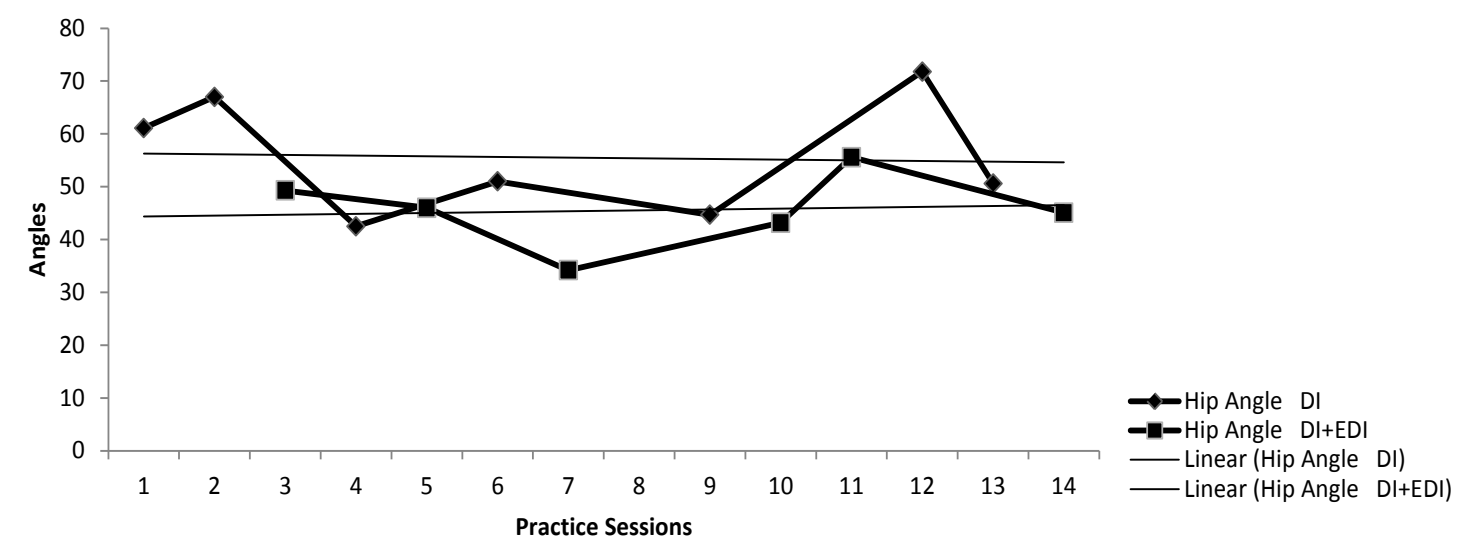

Figure 3. Mark's hip angle for running tuck jump.

Participant 4 (Tim). Participant 4 will be referred to as "Tim" (fictitious name).

Figure 4 displays the results of Tim's hip angle in the skill of running tuck jump. Tim's mean hip angle in the DI session was 60.1 degrees. His mean hip angle was smaller at 38 degrees in the DI+EDI session. Tim's hip angle in both DI and DI+EDI had similar downward trends (trend $=-1.32$ in DI, trend $=-1.43$ in DI+EDI). The variability of Tim's hip angle in $\mathrm{DI}$ was $\mathrm{SD}=11.9 \mathrm{~cm}$. The variability of his hip angle in $\mathrm{DI}+\mathrm{EDI}$ was $\mathrm{SD}=6.5$ $\mathrm{cm}$. Thus, DI+EDI appeared to have produced lower performance variability.

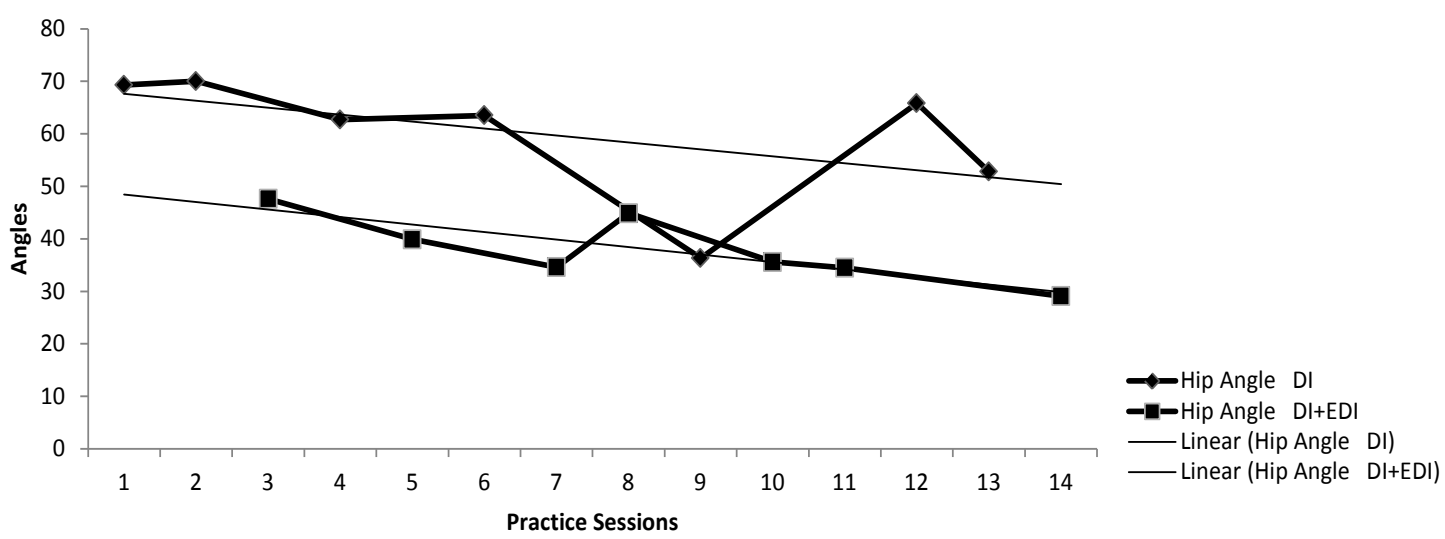

Figure 4. Tim's hip angle for running tuck jump. 


\section{Back angle.}

Participant 1 (Adam). Figure 5 displays the results of Adam's back angle in the skill of tuck jump. Adam's mean back angle in the DI was 17 degrees. His mean back angle was less (14.5 degrees) in DI+EDI. Adam's back angle in DI had an upward trend (trend $=0.72$ ). His back angle in DI+EDI had nearly no trend (trend $=0.023$ ). The variability of Adam's back angle in $\mathrm{DI}$ was $\mathrm{SD}=7$ degrees. The variability of his back angle in $\mathrm{DI}+\mathrm{EDI}$ was $\mathrm{SD}=4.6$ degrees. Thus, $\mathrm{DI}$ appeared to produce more variability in Adam's back angle.

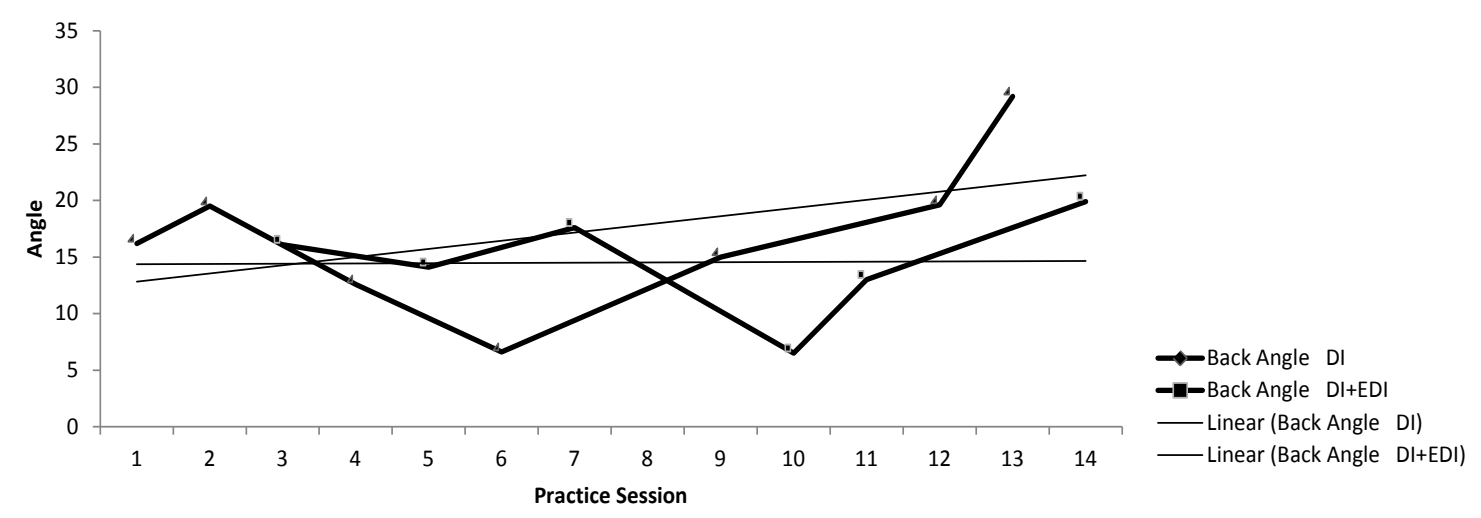

Figure 5. Adam's back angle for running tuck jump.

Participant 2 (Harry). Figure 6 displays the results for Harry's back angle in the skill of running tuck jump. Harry's mean back angle in DI was 17.2 degrees. His mean back angle in DI+EDI was greater at 31.3 degrees. Harry's back angle in DI had almost no trend (trend $=-0.03$ ). His back angle in DI+EDI had an upward trend (trend=0.92). The variability for Harry's back angle in $\mathrm{DI}$ was $\mathrm{SD}=8.1$ degrees. The variability for his back angle in $\mathrm{DI}+\mathrm{EDI}$ was $\mathrm{SD}=4.5$ degrees. Thus, $\mathrm{DI}+\mathrm{EDI}$ appeared to have reduced performance variability. 


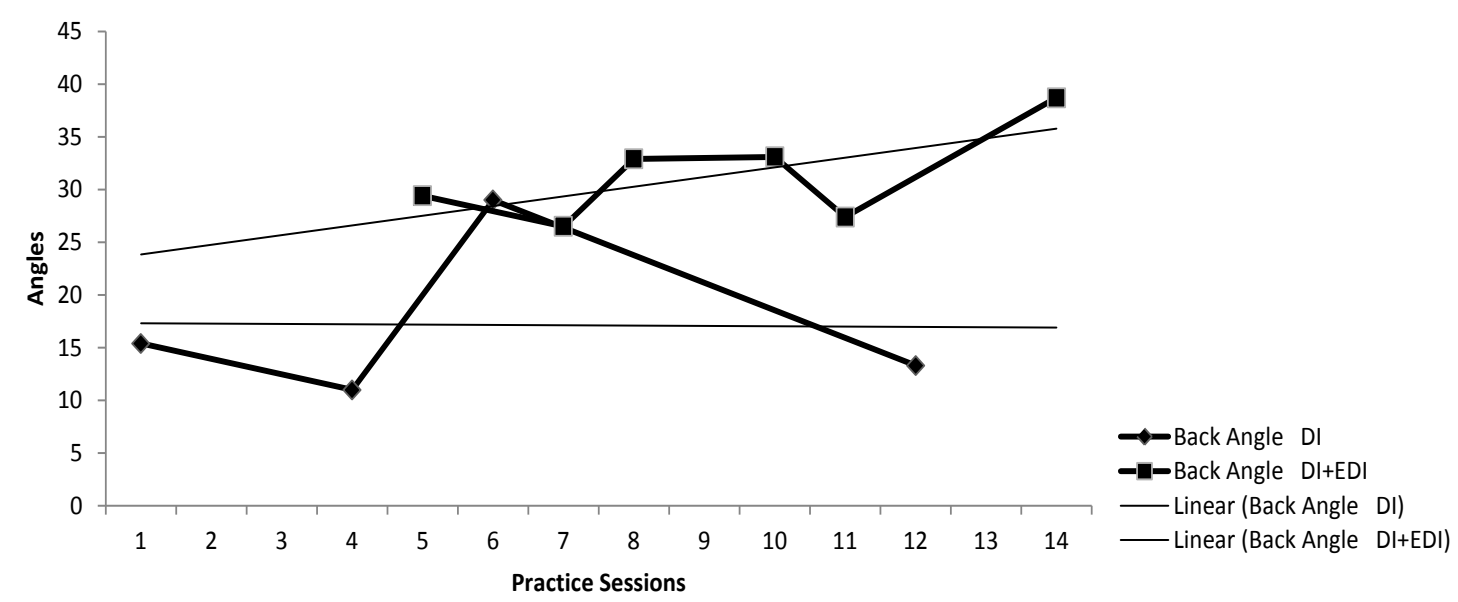

Figure 6. Harry’s back angles for running tuck jump.

Participant 3 (Mark). Figure 7 displays the results of Mark's back angle for running tuck jump. Mark's mean back angle in DI was 22.1 degrees. His mean back angle was larger at 32.4 degrees in DI+EDI. Mark's back angle in DI had an upward trend (trend $=0.83$ ). His trend in DI+EDI was negligible (trend $=0.32)$. The variability of Mark's back angle in both DI and DI+EDI was about the same (SD=6.2 degrees for DI, $\mathrm{SD}=6.3$ degrees for $\mathrm{DI}+\mathrm{EDI})$.

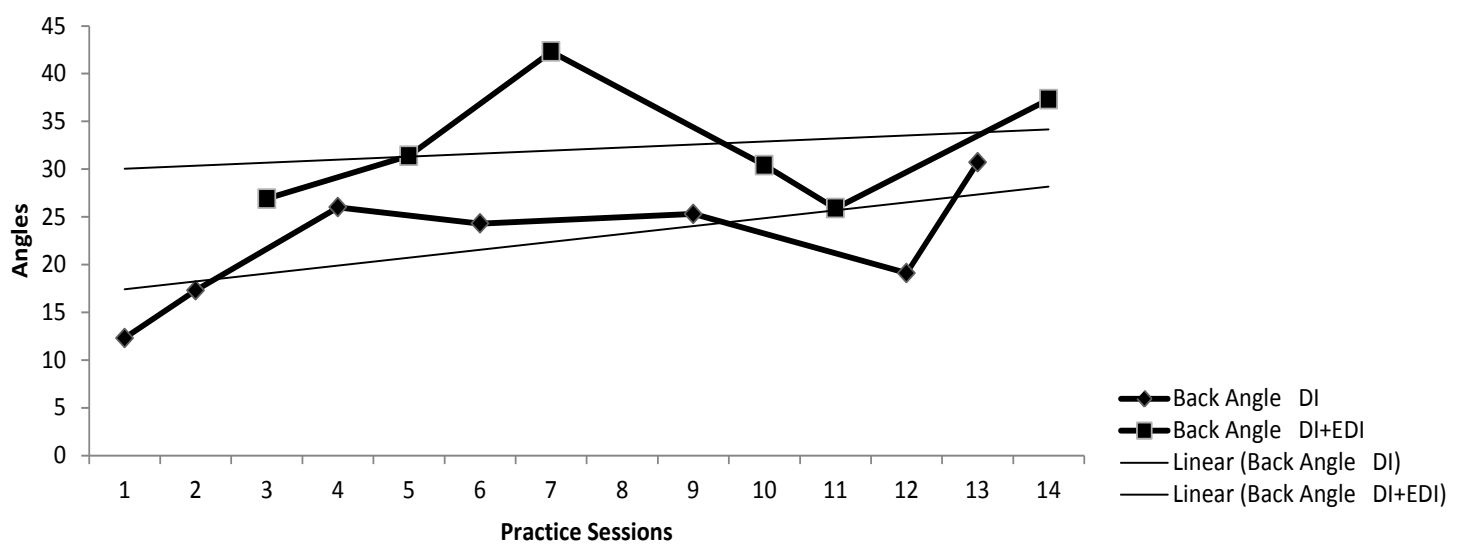

Figure 7. Mark's back angle for running tuck jump. 
Participant 4 (Tim). Figure 8 displays the results of Tim's back angle in the skill of running tuck jump. Tim's mean back angle in DI was 21.8 degrees. His mean back angle was larger at 39.4 degrees in DI+EDI. Tim's back angle in both DI and DI+EDI had almost no trends (trend $=0.1$ for $\mathrm{DI}$, trend $=0.15$ for $\mathrm{DI}+\mathrm{EDI})$. The variability for Tim's back angle in DI was $\mathrm{SD}=6.6$ degrees. The variability of his back angle in DI+EDI was $\mathrm{SD}=7.8$ degrees. Thus, variability for both conditions was essentially the same for back angle.

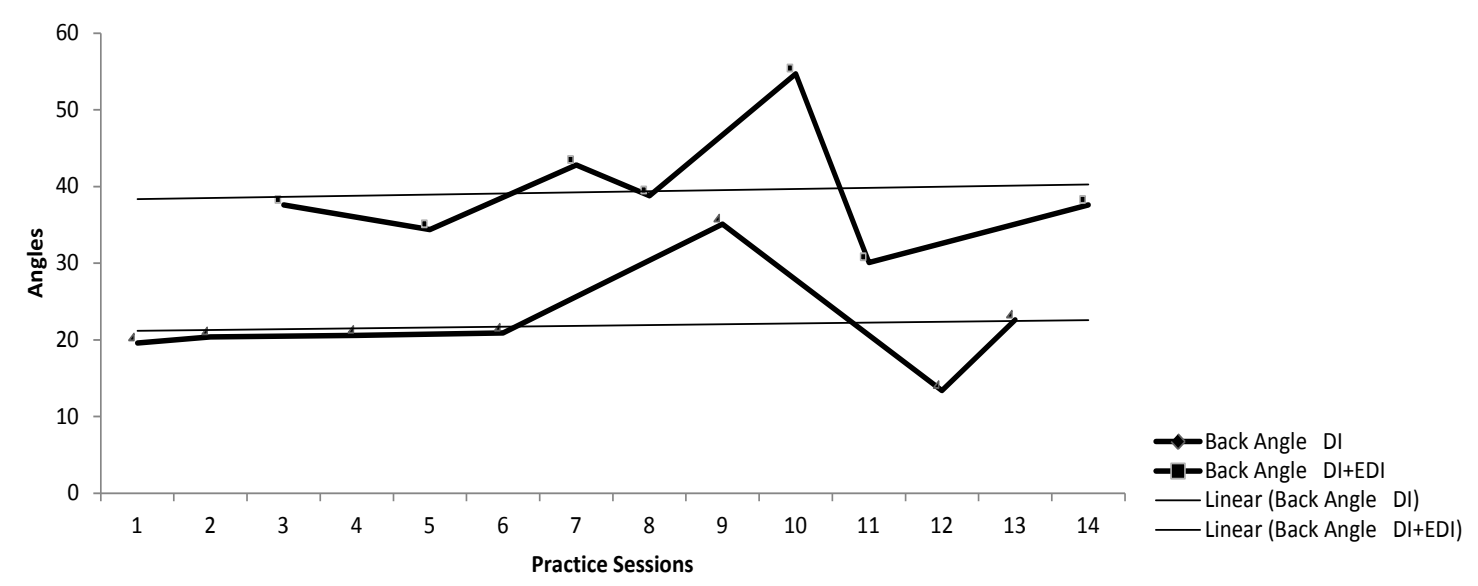

Figure 8. Tim’s back angle for running tuck jump.

\section{Jump height.}

Participant 1 (Adam). An adjustable hurdle was placed in front of the springboard for Adam's EDI set up. The experiment of the running tuck jump for Adam includes seven DI and six DI+EDI, with each instruction alternating with the other. The height of the hurdle when implementing EDI was always at least three centimeters higher than the previous mean body height when Adam performed the running tuck jump taught by DI except one session day. 
Figure 9 displays the results for Adam's jump height in the skill of running tuck jump. Adam's mean running tuck jump height in DI was $73.6 \mathrm{~cm}$. His mean jump height was higher at $86.8 \mathrm{~cm}$ in DI+EDI. Adam's jump height for DI had an upward trend (trend $=0.92$ ). However, his jump height trend for DI+EDI was negligible (trend $=0.2$ ). The variability of Adam's jump height in $\mathrm{DI}$ was $\mathrm{SD}=6.2$. The variability of his jump height in DI+EDI was $\mathrm{SD}=5$. Thus, DI and DI+EDI produced similar variability.

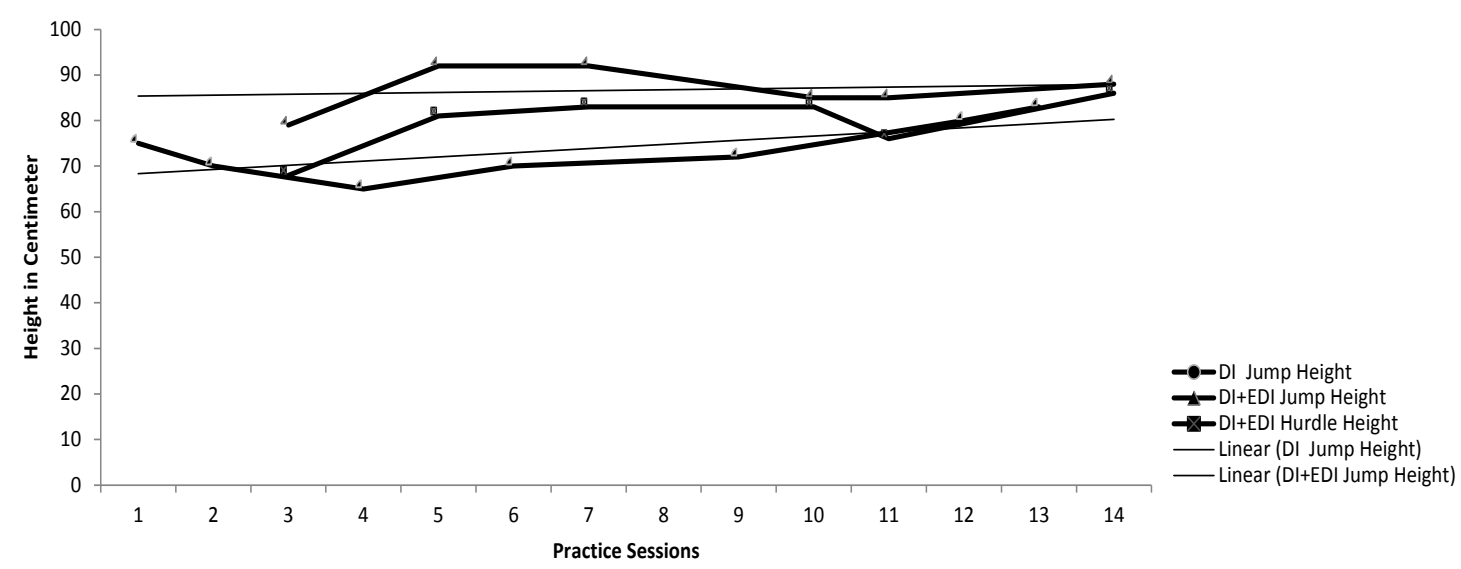

Figure 9. Adam's jump height for running tuck jump.

Participant 2 (Harry). An adjustable hurdle was placed in front of the springboard for Harry's EDI set up. The experiment of the running tuck jump for Harry included four DI sessions and six sessions of DI+EDI with one instruction (DI or DI+EDI) alternated with the other (DI+EDI or DI) five times. The height of the hurdle when implementing for EDI was always three centimeters higher than the previous mean body height when Harry performed the running tuck jump taught by DI.

Figure 10 displays the results for Harry's jump height in running tuck jump. Harry's mean jump height in DI was $75.5 \mathrm{~cm}$. His mean jump height was higher at 87.2 
$\mathrm{cm}$ in DI+EDI. The trends of Harry's jump height in both DI and DI+EDI were negligible (trend $=0.35$ for DI, trend $=-0.2$ for DI+EDI).The variability of Harry's jump height in $\mathrm{DI}$ was $\mathrm{SD}=3.4 \mathrm{~cm}$. The variability of his jump height in $\mathrm{DI}+\mathrm{EDI}$ was $\mathrm{SD}=1.8$ $\mathrm{cm}$. Thus, variability was low in both conditions for jump height.

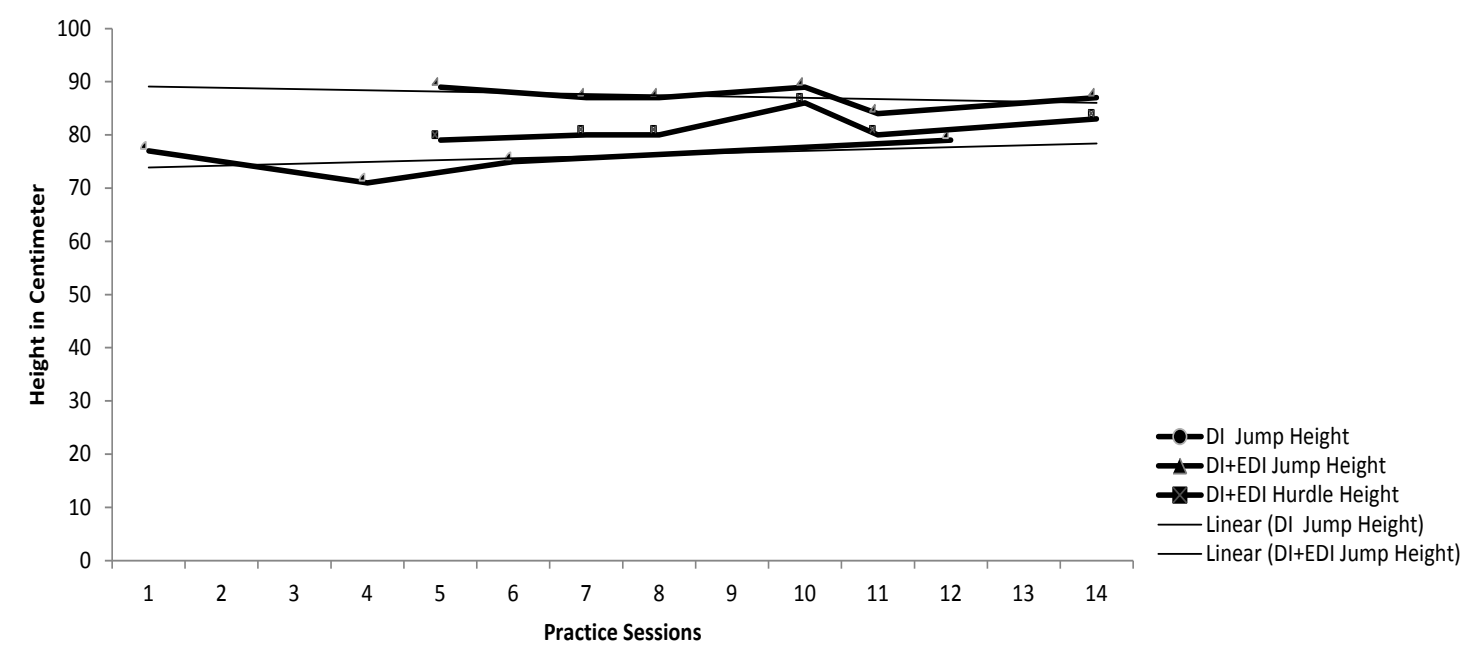

Figure 10. Harry's jump height for running tuck jump.

Participant 3 (Mark). An adjustable hurdle was placed in front of the springboard for Mark's EDI set up. The experiment of the running tuck jump for Mark included seven DI sessions and six sessions of DI+EDI with one sessions (DI or DI+EDI) alternated with the other (DI+EDI or DI) nine times. The height of the hurdle when implementing EDI was at least three centimeters higher than the previous mean body height when Mark performed the running tuck jump taught by DI.

Figure 11 displays the results of Mark's running tuck jump height. Mark's mean jump height in DI was $78.9 \mathrm{~cm}$. His mean jump height was higher at $98.2 \mathrm{~cm}$ in DI+EDI. As seen in Figure 11, Mark's jump height in DI had an upward trend (trend=1.24). His 
jump height trend in DI+EDI was negligible (trend=-0.4). The variability of Mark's jump height in $\mathrm{DI}$ was $\mathrm{SD}=5.1 \mathrm{~cm}$. The variability of his jump height in $\mathrm{DI}+\mathrm{EDI}$ was $\mathrm{SD}=4.1$ $\mathrm{cm}$. Thus, both DI and DI+EDI produced similar performance variability.

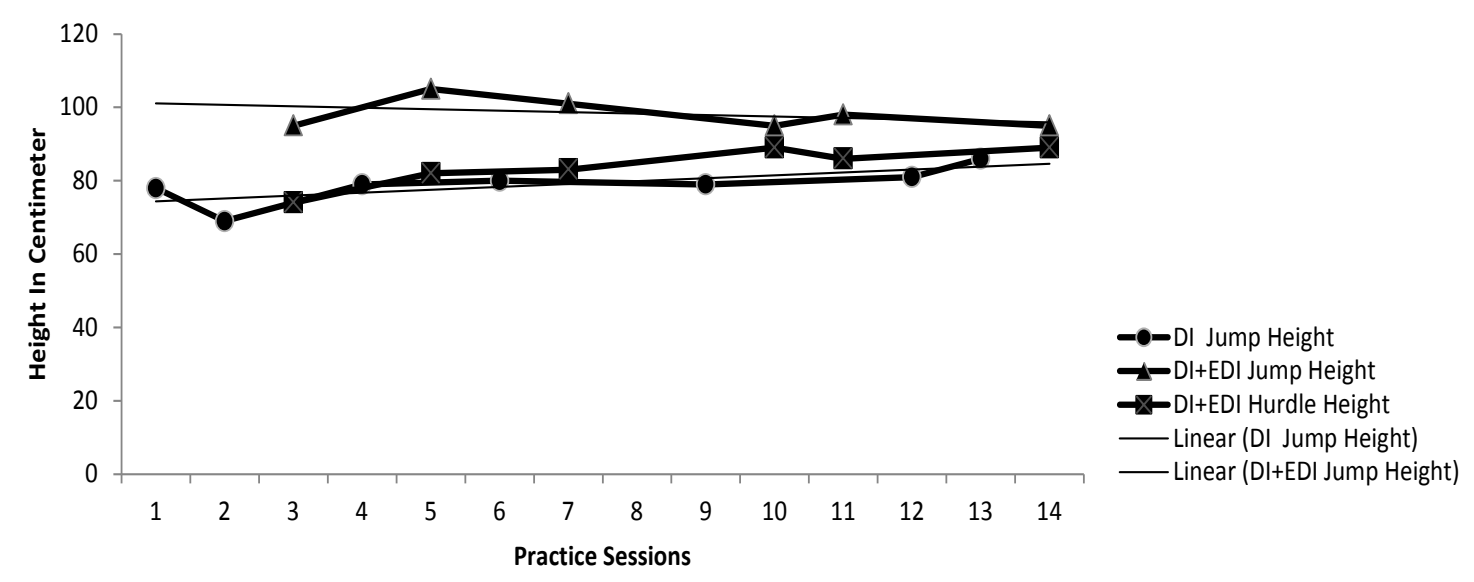

Figure 11. Mark's jump height for running tuck jump.

Participant 4 (Tim). An adjustable hurdle was placed in front of the springboard for Tim's EDI set up. The experiment of the running tuck jump for Tim included seven DI sessions and seven sessions of DI+EDI with one session (DI or DI+EDI) alternated with the other (DI+EDI or DI) nine times. The height of the hurdle when implementing EDI was always at least one centimeter higher (with one exception session which is during the first DI+EDI day, and following the requests of two participants to set the hurdle lower than the previous mean jump height taught by DI) than the previous mean jump height when Tim performed the running tuck jump taught by DI.

Figure 12 displays the results for Tim's running tuck jump height. Tim's mean jump height in DI was $84 \mathrm{~cm}$. His mean jump height in DI+EDI was higher at $97.4 \mathrm{~cm}$. Tim's jump height in DI had a slightly upward trend (trend=0.72). His jump height in 
DI+EDI was negligible (trend=0.54).viewed as upward trend. The variability of Tim's jump height in $\mathrm{DI}$ was $\mathrm{SD}=4.8 \mathrm{~cm}$. The variability of his jump height in DI+EDI was $\mathrm{SD}=3.1 \mathrm{~cm}$. Thus, $\mathrm{DI}+\mathrm{EDI}$ seemed to produce slightly lower performance variability than DI.

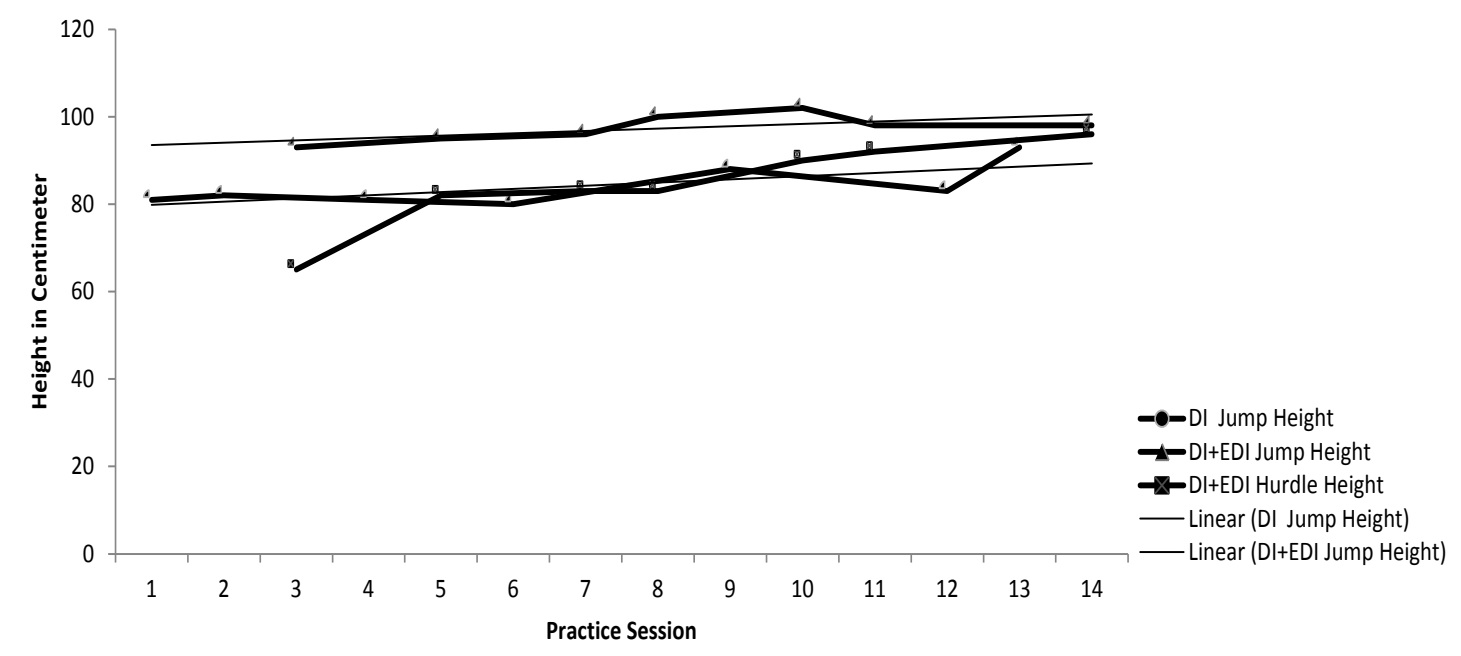

Figure 12. Tim's jump height for running tuck jump.

In summary, the first experiment used alternating treatment design to compare the effects of DI with DI+EDI on running tuck jump. Three variables were analyzed in the skill of running tuck jump. Those three variables were: (1) participants' hip angle while jumping at the highest point, (2) participants' back angle while jumping at the highest point, and (3) participants' jump height at the highest point. A good gymnast who performs a quality running tuck jump needs to tighten the knees, straight up the back, and have a high jump while jumping at the highest point. In order words, the smaller the hip and back angle, the higher the jump height, the better a performance would be. 
The data of the running tuck jump for those four participants while jumping in the air indicated that the hip angle was smaller in DI+EDI than in DI. Three out of four participants' mean hip angle was reliably smaller in DI+EDI than in DI. One participant's mean hip angle was just slightly smaller in DI. These data indicated that compared with DI, DI+EDI could better help tightening up the knees when participants jumped at the highest point.

One participant's hip angles had downward trend in DI while two other participants had downward trends in DI+EDI. There were also other two participants in DI and one participant in DI+EDI whose hip angle had almost no trends. One participant's trend in DI was negligible, and there was also one participant whose hip angle had upward trend in DI+EDI. These findings indicated that DI+EDI might be slightly better in producing downward trend in participants' hip angles. One participant had no trends in both conditions and another participant had upward trend in both conditions also one condition's trend is negligible. These findings also indicated that both teaching methods may not have sufficient effects in improving hip-angle-form continuously for two participants.

Standard deviation of the data show that DI+EDI produced less data variability for the four participants compared with DI. These data indicated that participants' hip angles were more stable in DI+EDI compared with DI. The findings that DI+EDI was more helpful in decreasing participants' hip angle at the highest point when they were performing a running tuck jump is understandable. The environmental condition (an adjustable hurdle placed in front of the participants and the springboard) forced 
participants to bring their knees close to the chest which decreased the hip angle in order to jump over the hurdle.

Three participants' mean back angle was reliably smaller in DI while only one participant's mean back angle was just slightly smaller in DI+EDI. The data of mean back angle showed that DI could better help decrease the mean back angle. In other words, participants' backs were straighter at the highest point when they were taught by DI.

There were two participants in DI and three participants in DI+EDI who had no or negligible trends in back angle. Two participants in DI and one participant in DI+EDI had upward trends. Trend data showed that neither of the two conditions could continuously help straightening up (downward trend) back for any of the participants while they were jumping at the highest point.

The data of SD show that DI produced more variability in back angle data for two participants, while the other two participants' data variability was similar in both conditions. These findings indicated that DI+EDI may be slightly better in controlling the variability of back angle.

The data of jump height in the running tuck jump indicated that participants, when implementing DI+EDI, could always jump over the adjusted hurdle. And because the hurdle was always higher than the previous mean jump height in DI, the mean jump height in DI+EDI was much higher than DI for all participants.

Two participants had upward jump height trends in DI and their trends in DI+EDI were negligible. There was one participant whose jump height trends were negligible in 
both conditions. Only one participant had upward jump height trend in both conditions. SD data show that DI+EDI might be more helpful in controlling the variability of jump height.

\section{Experiment 2 (Mushroom Circles)}

In the skill of mushroom circles, two dependent variables were analyzed. These two dependent variables were (1) the angle between the torso and the lower body (torso angle), and (2) the angle between the torso and the arm (arm angle).

All six DI sessions were checked for the fidelity of teacher's behavior. Because of the fact that all participants have already learned the skill of mushroom circle and watched the teachers' demonstration for multiple times before, the teacher in the current study did not demonstrate the skill for each session day. The results indicated that the teacher demonstrated the skill of mushroom circles in two DI session days (the first and third DI session days). The teacher provided cues before letting the participants perform the skill for all six DI session days. The teacher also provided feedback to each participant following each set of their performance for all six DI session days.

\section{Torso angle.}

Participant 1 (Adam). Figure 13 displays the results for Adam's torso angle in mushroom circles. Adam's mean torso angle in DI was 155.8 degrees. His mean torso angle in the DI+EDI was 149.2 degrees. Adam's mean torso angle in DI was larger by 6.6 degrees. As noted in Figure 13, a downward trend was observed for Adam's torso angle under DI+EDI (trend=-0.92). His torso angle trend in DI was negligible (trend=0.24). The variability of Adam's torso angle for $\mathrm{DI}$ was $\mathrm{SD}=2.4$. The variability of 
Adam's torso angle for $\mathrm{DI}+\mathrm{EDI}$ was $\mathrm{SD}=3.6$. Thus, variability was not appreciably different between DI and DI+EDI for Adam's torso angle.

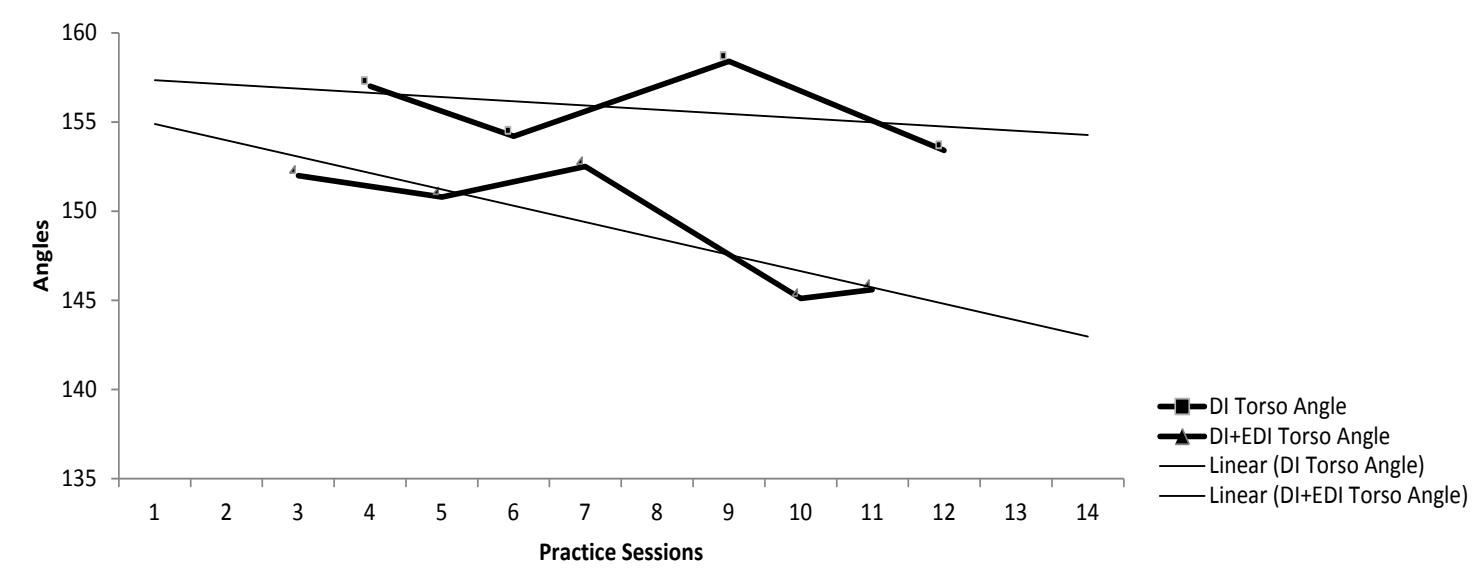

Figure 13. Adam's torso angle for mushroom circles.

Participant 2 (Greg). Participant 2 will be referred to as "Greg" (fictitious name).

Figure 14 displays the results of Greg's torso angle for mushroom circles. Greg's mean torso angle in DI was 161.1 degrees. His mean torso angle was 159.1 degrees in DI+EDI. Thus, there was no appreciable difference in the level of torso angle for Greg. As noted in Figure 14, the torso angle trends for both DI and DI+EDI were negligible (trend $=-0.29$ for DI, trend=-0.14 for DI+EDI). The variability of Greg's torso angle for DI was SD=3.0 degrees. The variability of his torso angle for $\mathrm{DI}+\mathrm{EDI}$ was $\mathrm{SD}=1.9$ degrees. Thus, neither method produced excessive variability. 


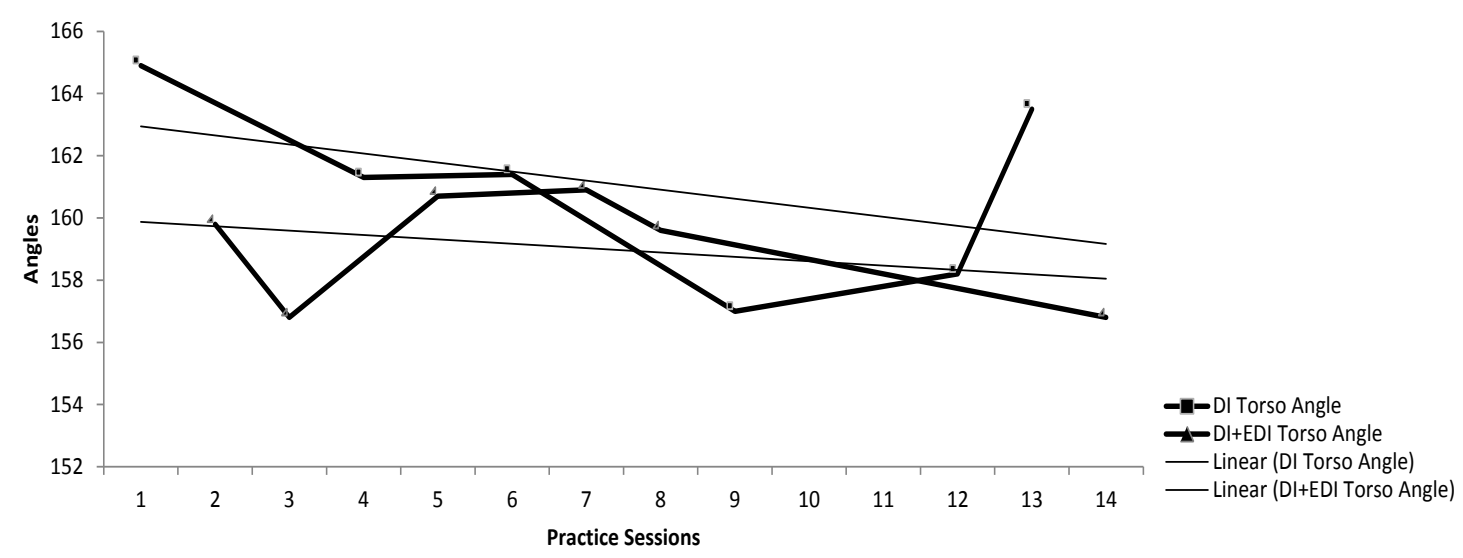

Figure 14. Greg's torso angle for mushroom circles.

Participant 3 (Neil). Participant 3 will be referred to as "Neil" (fictitious name).

Figure 15 displays the results of Neil's torso angle for mushroom circles. Neil's mean torso angle in DI was 162.6 degrees. His mean torso angle was smaller at 154.1 degrees in DI+EDI. As noted in Figure 15, the torso angle in both DI and DI+EDI had downward trends, although the DI trend was nearly non-existent (trend $=-0.76$ for DI, trend $=-0.22$ for $\mathrm{DI}+\mathrm{EDI})$. The variability for Neil's torso angle in $\mathrm{DI}$ was $\mathrm{SD}=6.5$ degrees. The variability of Neil's torso angle data in $\mathrm{DI}+\mathrm{EDI}$ was $\mathrm{SD}=5.7$ degrees. Thus, the variability for torso angle was similar for Neil. 


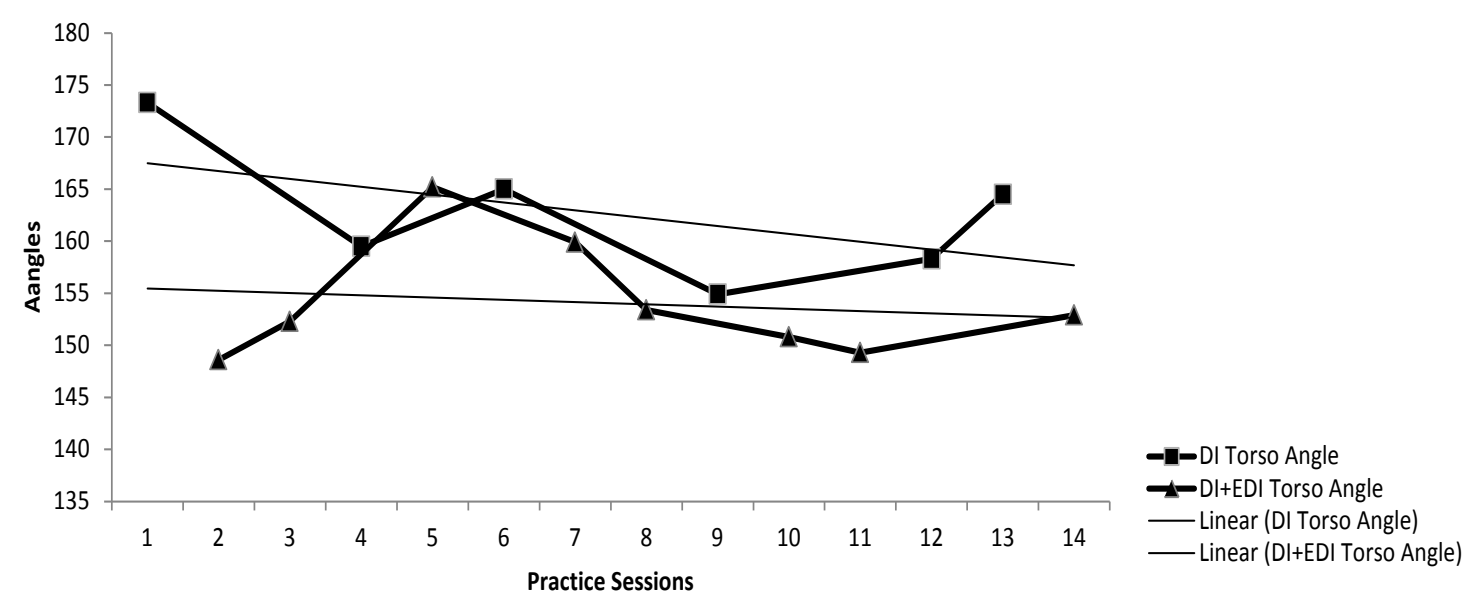

Figure 15. Neil's torso angle for mushroom circles.

Participant 4 (Tim). Figure 16 displays the results of Tim's torso angle in mushroom circles. Tim's mean torso angle in DI was 173.6 degrees. His mean torso angle was smaller at 168.4 degrees in DI+EDI. The torso angle in both DI and DI+EDI had a downward trend, although both trends were negligible (trend $=-0.45$ for DI, trend $=-$ 0.21 for $\mathrm{DI}+\mathrm{EDI})$. The variability of torso angle in $\mathrm{DI}$ was $\mathrm{SD}=3.8$ degrees. The variability of torso angle was similar in $\mathrm{DI}+\mathrm{EDI}$ at $\mathrm{SD}=3.9$ degrees.

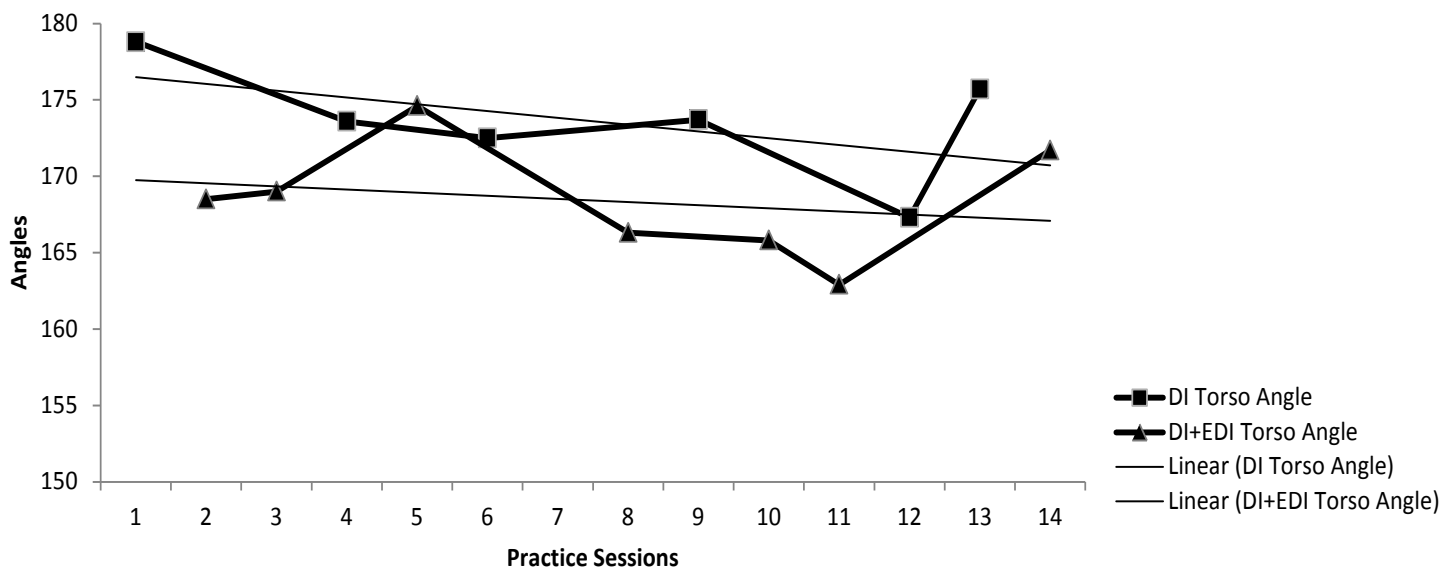

Figure 16. Tim's torso angle for mushroom circles. 


\section{Arm angle.}

Participant 1 (Adam). Figure 17 displays the results of Adam's arm angle in mushroom circles. Both DI and DI+EDI produced similar mean arm angle (mean arm angle $=18$ degrees for DI, mean arm angle $=18.4$ degrees for DI+EDI). As noted in Figure 17, Adam's arm angle for DI+EDI had a downward trend (trend=-1.37). His arm angle trend for DI was negligible (trend=-0.34). The variability of Adam's arm angle for DI was $\mathrm{SD}=2.1$ degrees. The variability of his arm angle for $\mathrm{DI}+\mathrm{EDI}$ was $\mathrm{SD}=4.9$ degrees. Thus, arm able was more stable for Adam under DI.

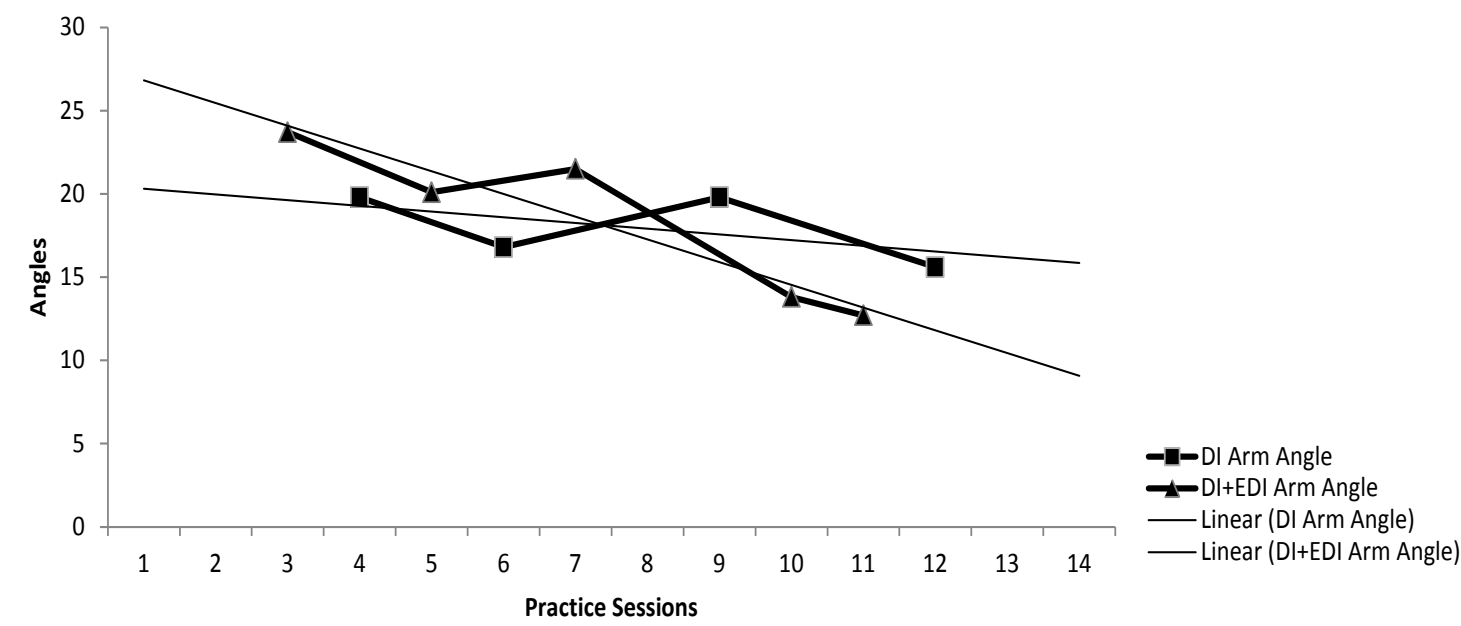

Figure 17. Adam's arm angle for mushroom circles.

Participant 2 (Greg). Figure 18 displays the results of Greg's arm angle for mushroom circles. Greg's mean arm angle in DI was 17.6 degrees. His mean arm angle was only slightly higher (18.7 degrees) in DI+EDI. As noted in Figure 18, Greg's arm angle for both DI and DI+EDI had negligible and similar trends (trend=-0.15 for DI, trend=-0.19 for DI+EDI). The variability of Greg's arm angle for DI was $\mathrm{SD}=1.4$ degrees. 
The variability of his arm angle for $\mathrm{DI}+\mathrm{EDI}$ was $\mathrm{SD}=1.8$ degrees. Thus, very little difference in variability was apparent in arm angle for Greg.

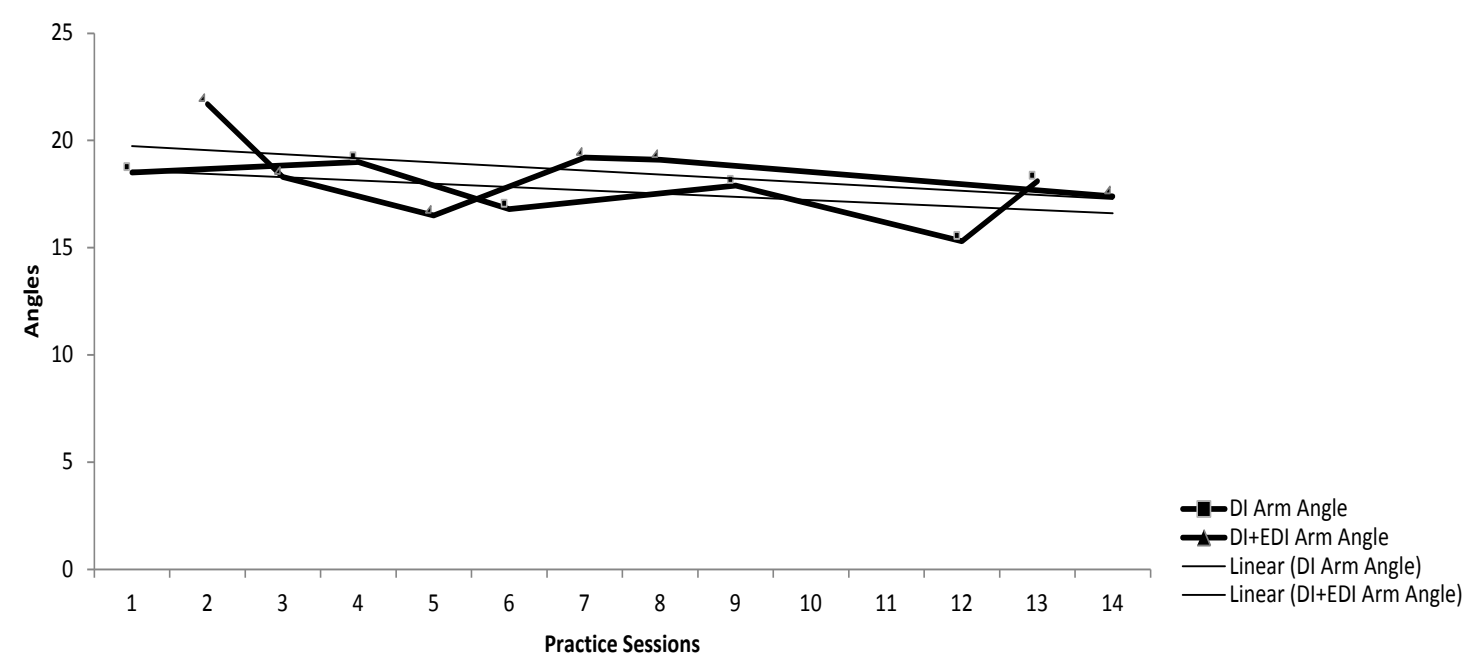

Figure 18. Greg's arm angle for mushroom circles.

Participant 3 (Neil). Figure 19 displays the results of Neil's arm angle for mushroom circles. Neil's mean arm angle for DI was 24.5 degrees. His mean arm angle was slightly lower in DI+EDI at 21.7 degrees. As noted in Figure 19, the arm angle in both DI and DI+EDI had similar downward trends, and both trends were negligible (trend $=-0.32$ for DI, trend=-0.45 for DI+EDI). The variability of arm angle in DI was $\mathrm{SD}=3.3$ degrees. The variability of arm angle in $\mathrm{DI}+\mathrm{EDI}$ was $\mathrm{SD}=3.9$ degrees. Thus, variability in arm angle for Neil was similar in both methods. 


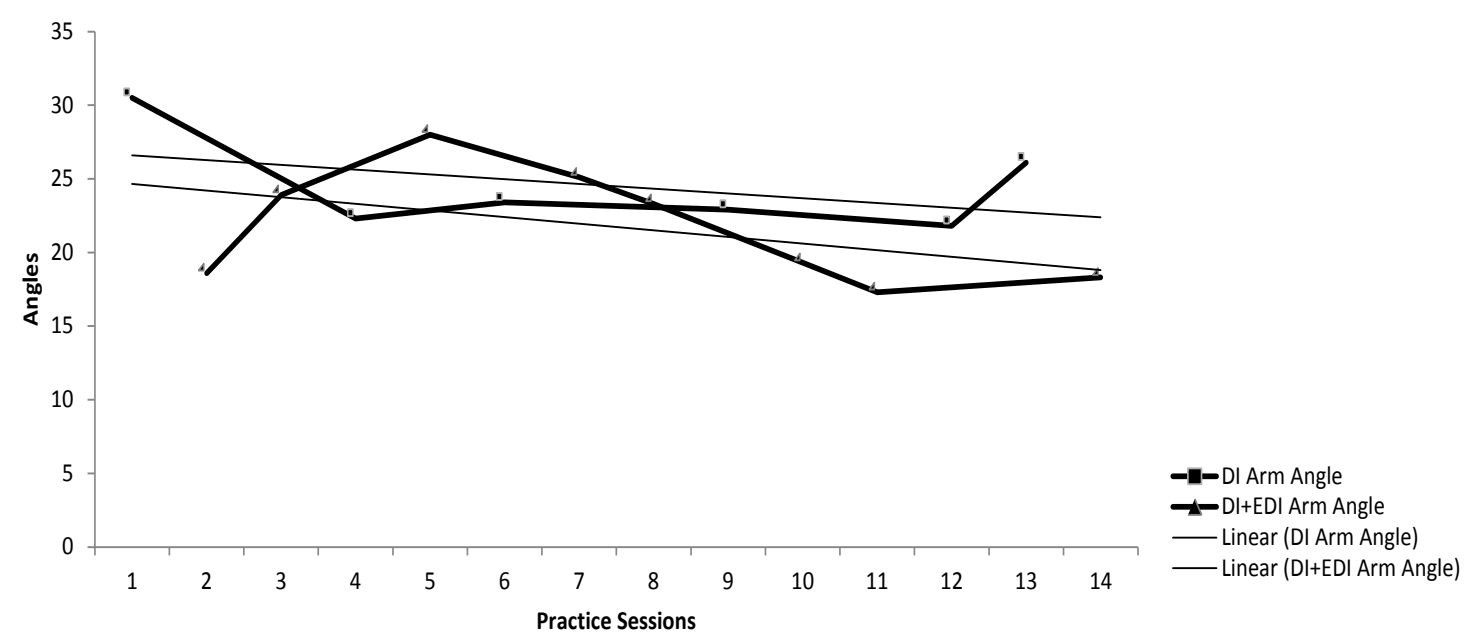

Figure 19. Neil's arm angle for mushroom circles.

Participant 4 (Tim). Figure 20 displays the results of Tim's arm angle in mushroom circles. Tim's mean arm angle in DI was 26.8 degrees. His mean arm angle was similar in DI+EDI at 27.5 degrees. Tim's arm angle for both DI and DI+EDI had similar downward trends although both trends were negligible (trend=-0.36 for DI, trend $=-0.47$ for DI+EDI). The variability of Tim's arm angle in DI was $\mathrm{SD}=2.1$ degrees. The variability of his arm angle in $\mathrm{DI}+\mathrm{EDI}$ was similar at $\mathrm{SD}=2.8$ degrees.

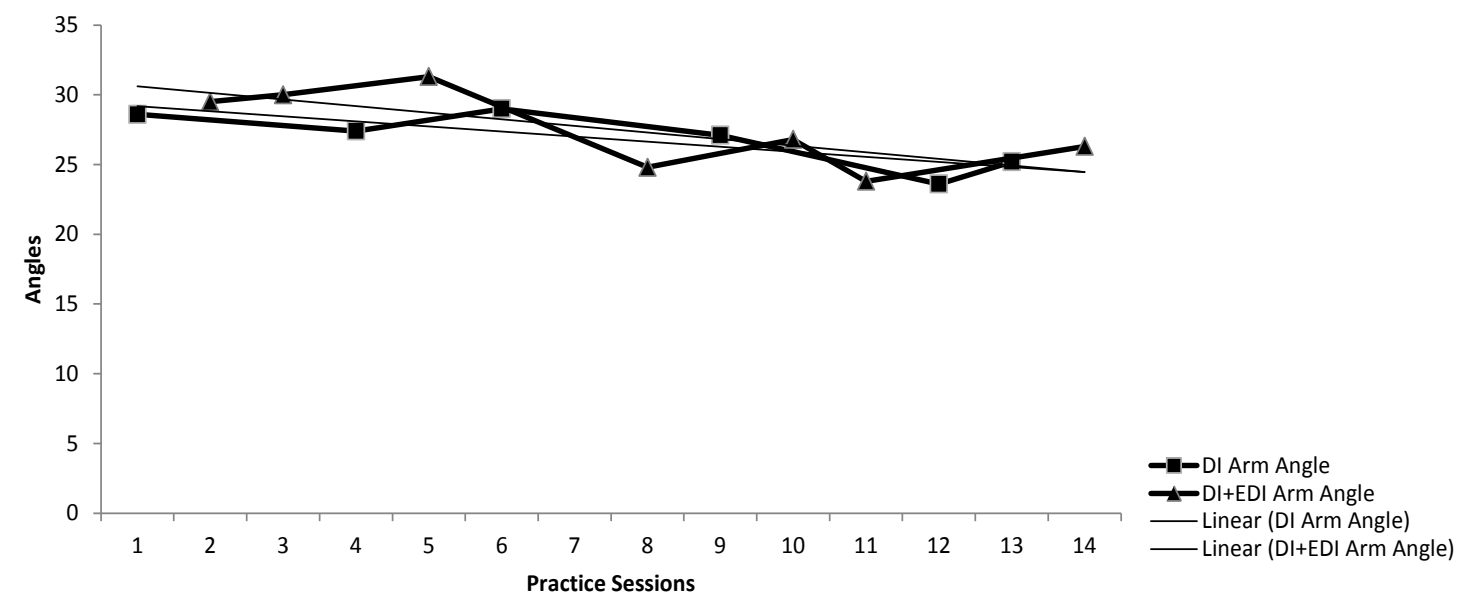


Figure 20. Tim's arm angle for mushroom circles.

In summary, the second experiment used alternating treatment design to compare the effects of DI with DI+EDI on mushroom circles. Two variables were analyzed in the skill of mushroom circles. They were (1) torso angle, and (2) arm angle. Quality mushroom circles need to fully extend the body which means the higher the torso and arm angle, the better a mushroom circle would be.

The findings showed that DI produced a larger mean torso angle than DI+EDI for all participants although the difference for one participant was negligible. There were no appreciable differences in torso angle trend taught by either of the method. Both conditions produced three participants whose torso angle trends were negligible, and one participant who had downward trend. The results of the SD indicated that the two conditions produced similar variability in torso angle.

The data of arm angle showed that both conditions produced similar mean arm angle for two participants. One participant's mean arm angle was slightly larger in DI+EDI while another participant's was slightly larger in DI. The trends were also similar and negligible in both conditions for three participants. There was also one participant who had negligible trend in DI and downward trend in DI+EDI. The data of SD showed that three participants' variability in arm angle were similar while only one participant's arm angle was more stable under DI.

The findings showed that the environmental condition (an object hung in front of the mushroom in a distance the participants' toes can barely touch it while performing 
mushroom circles) seems detrimental to the body extensions and increasing arm angle in the refinement of mushroom circles.

We also found that all participants' torso and arm angle had either downward or negligible trend in DI and DI+EDI. This finding indicated that neither of these two teaching methods could help participants with extending their bodies or opening arm angle continuously.

\section{CHAPTER FIVE}

\section{Discussion}

The findings of these two experiments indicated that for easy skills like the running tuck jump, DI+EDI worked better for participants in bringing knees closer to their chest at the highest point and jumping higher than DI. However, DI+EDI caused a more negative effect on the students' back angle than DI by letting their back lean forward while jumping at the highest point. For hard skills such as mushroom circles, DI+EDI was not better or even worse than DI in helping students' body extension and opening arm angle in mushroom circles, although participants' form did not have an improving trend in either of the teaching methods.

The findings that DI was more helpful in straightening participants' back when they jump at the highest point may be explained by the teacher's behaviors. Direct instruction requires the teacher to provide all critical elements of running tuck jump before students practice. In our study, the teacher emphasized the importance of a straight back at the highest point. Providing feedback is also one of the characteristics of DI. The teacher in the current study provided feedback on how to improve the quality of the skill 
after each participant finished his try. However, when an environmental condition was implemented (hurdle placed in front of the springboard), the participants' attention was to bring their knees close to the chest (decrease the hip angle) in order to jump over the hurdle. Leaning forward made it easier and quicker for them to bring knees to the chest. So, even though the teacher required the students to keep their backs straight at the highest point before and after their practice, the students were in a hurry in jumping over the hurdle and therefore had to lean forward to bring their knees to the chest.

The study found DI might be more helpful in producing upward trend in jump height. This finding may be attributed to several factors including continuous practice and the effects of both DI and DI+EDI methods. Three participants' negligible trends in DI+EDI may be explained by the specific environmental conditions (the height of the hurdle) and the decreased motivation towards jumping over the hurdle. Because the height of the hurdle was based on participants' previous mean jump height taught under DI, and the hurdle's height had not been continuously raised up for all these three participants (there was one out of six times in which the hurdle's height was lower than the previous hurdle height for these three participants). The decreased hurdle height for one time may be one of the explanations for the negligible trend of jump height for these three participants. Another possible explanation is that the participants might gradually have lost the motivation toward the environmental condition, which decreased the jump height in DI+EDI.

The finding that DI+EDI might be more helpful in controlling the variability of the jump height is understandable as participants' jump height could be influenced by many factors (e.g., mood, temperature) when taught in DI. Although those factors still exist in 
DI+EDI, the hurdle was placed as a standard for participants to jump over which decreased the variability of the jump height in DI+EDI.

The negative effects of the EDI in the experiment of mushroom circles may be due to the inappropriate design of the environmental condition and the hard-to-refine nature of the skill. First, when analyzing the video, we saw some participants moving their hands forward on the mushroom while performing mushroom circles in order to touch their toes at the object hung in front of the mushroom. Moving hands forward (or backward) while performing mushroom circles could cause unbalance on the performance, therefore the participants' focus was on keeping balance and could not maintain the ability to extend their body and (or) open the arm angle. Second, the skill of mushroom circles is a relatively difficult gymnastics skill. Maintaining fully extended body and opening arm angle while performing mushroom circles require not only skill practice but also some auxiliary practice such as arms, back, and abdominal muscular, and body arms flexibility training. The limited practice sessions during our study also made it hard to help extending participants' body and opening the arm angle in their mushroom circles.

The findings show that neither of the two teaching methods in the experiment of mushroom circles could help participants with extending bodies or opening arm angle continuously. A possible explanation is that the participants gradually lost the motivation of extending their bodies or opening arm angle and may need additional stimuli. This finding may also be evidence that purely practice with DI could not help refine the forms of the difficult skill of mushroom circles. 
These findings might indicate that DI+EDI could only help improving easy skills' form. This finding correlates with previous studies supporting the effects of EDI on easy skill's (standing broad jump) form improvement (Sweeting \& Rink, 1999). However, although DI+EDI was more helpful in decreasing hip angle and increasing jump height, there were two participants hip angle who had either no or upward trend in DI+EDI, and three participants jump height trends were negligible. In the experiment of mushroom circles, all participants had either downward or negligible trends in both torso and arm angles in DI+EDI. These findings may indicate that the environmental condition possibly lost its motivating effect for the participants (Sweeting \& Rink, 1999). According to Rink (2001), one of the keys to student engagement is student motivation, and instructors need to create environmental conditions to improve students' motivations in an effort to enhance students' engagement. This also supports Sweeting and Rink's (1999)'s comments that motivation issues relate to novelty. In our study, the environmental condition was the same in the experiment of running ruck jump (hurdle in front of the springboard) and mushroom circles (string in front of the mushroom), which might lose participants' motivation as evidenced by trend data.

Future studies should explore the effects of alternating different environmental conditions on the skills' performance. Sweeting and Rink (1999) also commented that the reduced effects of the environmental condition might also due to the participants having acquired the skill and therefore they were restricted by the environmental condition. Thus, another explanation for the upward or no trend in hip angle, and negligible trends in jump height for some participants in DI+EDI in running tuck jump is that those participants had reached their max ability to bring knees closer to their chest and jump height. 
The finding that DI+EDI was superior in improving parts of movements forms also corresponds with Sweeting and Rink's (1999) study in which they found that the swamp testing condition changed students arms at takeoff and truck and legs in flight in the standing long jump. This finding suggests not using DI+EDI all the time even though this method could help refine most of the forms of the running tuck jump. Teachers could use DI+EDI to help student bring kneed closer to the chest and jump higher. Once these two variables were refined, the teacher could switch to DI and focus on helping students straight up their back while jumping at the highest point. It is also a plausible idea to utilize different environmental conditions for different parts of the forms of the skill. And as suggested by Sweeting and Rink (1999), Future studies should explore the effects of different environments specifically designed for different parts of the movement.

The finding that DI+EDI was not better or even worse than DI on the skill of mushroom circles indicated the failure of the environmental condition of setting up the strings in front of the mushroom and requiring participants to touch toes at the string. The failure of this environmental condition may due to two reasons: (1) this environmental condition unexpectedly encouraged participants to move their hands forward on the mushroom in order to get their toes closer to the string, which caused body imbalance and had detrimental effects on the skill form, and (2) the strings could suddenly slow down the circles if participant's toes touched the string while performing mushroom circles, which also caused body imbalance and had a negative effect on the skill form.

Previous study also examined the effects of EDI on improving forms of difficult skill (Scott et al., 1997). The study examined an intervention that consisted of breaking a photoelectric beam with the hands at the moment of take-off while performing pole vault 
for an international-level athlete. They found that the height of the beam was gradually increased until the pole vaulter reached maximum arm extension at take-off, which resulted in an increase in bar height clearance. These findings seemed contradicted by our results in the experiment of mushroom circles considering that both mushroom circles and pole vault are relatively difficult skills. However, the pole vault study recruited an international-level athlete while the participants in the mushroom circles only practiced gymnastics for about three years. The limited practicing experience of the mushroom circles participants might make it hard for them to refine difficult skills with DI+EDI. This finding may suggest that the environmental condition could not help improving difficult skills unless the participant is high-leveled. It is also possible that other environmental interventions might be more successful than the string target in the current study. Future studies should explore different environmental conditions on the difficult skills. The downward or negligible trends for both torso and arm angles in either teaching method implied that neither of these two teaching methods could improve the skill forms continuously. This finding also questioned the effects of single DI and may suggest that auxiliary training such as muscular and/or flexibility practice is necessary in improving difficult skill forms such as mushroom circles.

The study demonstrated both positive and negative effects of DI+EDI on gymnastics skills. Teachers should be cautious in using DI+EDI as the content knowledge for the specific subject is required for teachers to set up the environmental design condition. Only teachers with content knowledge for a specific subject know the time to set up the environmental design condition or switch to a different condition in such a way to elicit skill performance. 


\section{References}

Allison, M. G., \& Ayllon, T. (1980). Behavioral coaching in the development of skills in football, gymnastics, and tennis. Journal of Applied Behavior Analysis, 13(2), 297.

Anderson, G., \& Kirkpatrick, M. A. (2002). Variable effects of a behavioral treatment package on the performance of inline roller speed skaters. Journal of Applied Behavior Analysis, 35(2), 195.

Ausubel, D., Novak, J., \& Hanesian, H. (1978). Educational psychology: A cognitive view.

Balan, C. M., \& Davis, W. E. (1993). Ecological Task Analysis-an Approach to Teaching Physical Education. JOPERD--The Journal of Physical Education, Recreation \& Dance, 64(9).

Barlow, D. H., \& Hayes, S. C. (1979). Alternating treatments design: one strategy for comparing the effects of two treatments in a single subject. Journal of Applied Behavior Analysis, 12(2), 199.

Barrett, D. D., \& Burton, A. W. (2002). Throwing patterns used by collegiate baseball players in actual games. Research Quarterly for Exercise \& Sport, 73(1), 19-27.

Belka, D. E. (1985). Effects of Selected Sequencing Factors on the Catching Process of Elementary School Children. Journal of Teaching in Physical Education, 5(1), $42-51$.

Bingham, G. P., Schmidt, R., \& Rosenblum, L. D. (1989). Hefting for a maximum distance throw: A smart perceptual mechanism. Journal of Experimental Psychology: Human Perception and Performance, 15(3), 507. 
Boyer, E., Miltenberger, R. G., Batsche, C., \& Fogel, V. (2009). Video modeling by experts with video feedback to enhance gymnastics skills. Journal of Applied Behavior Analysis, 42(4), 855.

Breslin, C. M., Garner, J. C., Rudisill, M. E., Parish, L. E., St Onge, P. M., Campbell, B. J. et al. (2009). The Influence of Task Constraints on the Glenohumeral Horizontal Abduction Angle of the Overarm Throw of Novice Throwers. Research Quarterly for Exercise and Sport, 80(2), 5.

Brobst, B., \& Ward, P. (2002). Effects of public posting, goal setting, and oral feedback on the skills of female soccer players. Journal of Applied Behavior Analysis, 35(3), 247.

Burton, A. W., \& Davis, W. E. (1996). Ecological task analysis utilizing intrinsic measures in research and practice. Human Movement Science, 15(2), 285-314.

Burton, A. W., Greer, N. L., \& Wiese-Bjornstal, D. M. (1993). Variations in grasping and throwing patterns as a function of ball size. Pediatric Exercise Science, 5(1), 2541.

Cooper, J. O., Heron, T. E., \& Heward, W. L. (2007). Applied Behavior Analysis (2nd Edition). Upper Saddle River, NJ: Pearson Prentice Hall.

Cross, R. (2004). Physics of overarm throwing. American Journal of Physics, 72, 305.

Davids, K., Button, C., \& Bennett, S. (2008). Dynamics of skill acquisition: a constraints-led approach: Human Kinetics Publishers.

Davis, W. E. (1986). Development of coordination and control in the mentally handicapped: Dordrecht: Martinus Nijhoff. 
Davis, W. E., \& Burton, A. W. (1991). Ecological Task Analysis: Translating Movement Behavior Theory Into Practice. Adapted Physical Activity Quarterly, 8(2), 154177.

Dell'Olio, J., \& Donk, T. (2007). Models of teaching: Connecting student learning with standards: Sage Publications, Inc.

Dunn, J., \& Fait, H. (1989). Special Physical Education: adapted, individualized, developmental (6th ed). Dubuque, IA: Wm. C. Brown.

Engelmann, S., \& Bruncer, E. C. (1969). DISTAR reading I (Teaching's presentation book, student material, and teacher's guide): Chicago: Science Research Associates.

Engelmann, S., \& Carnine, D. (1969). DISTAR arithmetic I (Teacher's presentation book, student material, and teacher's guide): Chicago: Science Research Associates.

Engelmann, S., \& Osborn, J. (1969). DISTAR language I (Teacher's presentation book, student material, and teacher's guide): Chicago: Science Research Associates.

Faldo, N. (1986). Putting: you must rock and roll on the greens In M. Wilson (ed.), The PGA European Tour Guide to Better Golf:: London: Pan Books.

French, K. E., Rink, J. E., Rikard, L., Mays, A., Lynn, S., \& Werner, P. H. (1991). The Effects of Practice Progressions on Learning Two Volleyball Skills. Journal of Teaching in Physical Education, 10(3), 261-274.

French, K. E., Rink, J. E., \& Werner, P. H. (1990). Effects of contextual interference on retention of three volleyball skills. Perceptual and Motor Skills, 71(1), 179-186.

Gibson, J. (1966). The Senses Considered as Perceptual Systems: Boston: Houghton Mifflin. 
Graham, G. (2008). Teaching children physical education: Becoming a master teacher: Human Kinetics Publishers.

Guerin, S., \& Kunkle, D. (2004). Emergence of constraint in self-organizing systems. Nonlinear Dynamics, Psychology, and Life Sciences, 8(2), 131-146.

Gusthart, J. L., \& Sprigings, E. J. (1989). Student Learning as a Measure of Teacher Effectiveness in Physical Education. Journal of Teaching in Physical Education, $8(4), 298-311$.

Isaacs, L. D. (1980). Effects of ball size, ball color, and preferred color on catching by young children. Perceptual and Motor Skills, 51(2), 583-586.

Joyce, B., Weil, M., \& Calhoun, E. (2009). Models of Teaching (8th ed.): Boston, Allyn and Bacon.

Kazdin, A. E. (1982). Single-case research designs: Methods for clinical and applied settings: Oxford University Press New York.

Kladopoulos, C. N., \& McComas, J. J. (2001). The effects of form training on foulshooting performance in members of a women's college basketball team. Journal of Applied Behavior Analysis, 34(3), 329.

Kugler, P. N. (1986). A morphological perspective on the origin and evolution of movement patterns. Motor development in children: Aspects of coordination and control, 459-525.

Kugler, P. N., Kelso, J. A. S., \& Turvey, M. (1980). On the concept of coordinative structures as dissipative structures: I. Theoretical lines of convergence. Tutorials in motor behavior, 3, 47. 
Kugler, P. N., Kelso, J. A. S., \& Turvey, M. (1982). On the control and coordination of naturally developing systems. The development of movement control and coordination, 5-78.

Kugler, P. N., \& Turvey, M. (1987). Information, natural law, and the self-assembly of rhythmic movement: L. Erlbaum Associates.

Liao, C. M., \& Masters, R. S. W. (2001). Analogy learning: a means to implicit motor learning. / Apprentissage par analogie: un moyen implicite d ' apprentissage moteur. Journal of Sports Sciences, 19(5), 307-319.

Lockwood, P., \& Penman, D. J. (2008). Enhancing the Youth Sport Experience: A Reexamination of Methods, Coaching Style, and Motivational Climate. Journal of Youth Sports, 4(1), 30-34.

Magliaro, S. G., Lockee, B. B., \& Burton, J. K. (2005). Direct Instruction Revisited: A Key Model for Instructional Technology. Educational Technology Research and Development, 53(4), 41-56.

Mellalieu, S. D., Hanton, S., \& O'Brien, M. (2006). The effects of goal setting on rugby performance. Journal of Applied Behavior Analysis, 39(2), 257.

Metzler, M. (1989). A Review of Research on Time in Sport Pedagogy. Journal of Teaching in Physical Education, 8(2), 87-103.

Miller, G. A. (1956). The magical number seven, plus or minus two: some limits on our capacity for processing information. Psychological Review, 63(2), 81-97. doi: $10.1037 / \mathrm{h} 0043158$

Morris, G. (1976). Effects ball and background color have upon the catching performance of elementary school children. Research Quarterly, 47(3), 409-416. 
. National Association for Sport and Physical Education (NASPE). (2008) Initial standards in physical education teacher education. Reston, VA: Author.

Newell, K. (1986). Constraints on the development of coordination. Motor development in children: Aspects of coordination and control, 341-360.

Rink, J. E. (2001). Investigating the assumptions of pedagogy. $<$ em $>$ Journal of Teaching in Physical Education</em>, 20(2), 112.

Rink, J. E. (2002). Teaching physical education for learning: McGraw-Hill.

Rink, J. E., French, K. E., Werner, P. H., Lynn, S., \& Mays, A. (1992). The Influence of Content Development on the Effectiveness of Instruction. Journal of Teaching in Physical Education, 11(2), 139-149.

Romanowich, P., Bourret, J., \& Vollmer, T. R. (2007). Further analysis of the matching law to describe two-and three-point shot allocation by professional basketball players. Journal of Applied Behavior Analysis, 40(2), 311.

Rosenshine, B. (1985). In T. Husen \& T. N. Postlethwaite (Eds.) Direct instruction. International Encyclopedia of Education (Vol. 3, pp. 1395-1400): Oxford: Pergamon Press.

Rosenshine, B., \& Furst, F. (1971). Research in teacher performance criteria In B. S. (Ed.) (Ed.), Research in teacher education: Englewood Cliffs, NJ: Prentice-Hall. Rosenshine, B., \& Stevens, R. (1986). Teaching functions. In M.C. Witrock (Ed.) Hand book of research on teaching (3rd ed., pp. 376-391): New York: Macmillan. Rukavina, P. B., \& Foxworth, K. R. (2009). Using Motor-Learning Theory to Design More Effective Instruction. Journal of Physical Education, Recreation \& Dance (JOPERD), 80(3), 17-23. 
Rutter, B. G. (1987). Towards an ecological model of prehension. University of Illinois, Urbana-Champaign (1987) Unpublished Doctoral Dissertation.

Scott, D., Scott, L. M., \& Goldwater, B. (1997). A performance improvement program for an international-level track and field athlete. Journal of Applied Behavior Analysis, 30(3), 573-575.

Shapiro, D. C., \& Schmidt, R. A. (1982). The schema theory: Recent evidence and developmental implications. The development of movement control and coordination, 113-150.

Shea, C. H., Wulf, G., Whitacre, C. A., \& Park, J.-H. (2001). Surfing the implicit wave. [Article]. Quarterly Journal of Experimental Psychology: Section A, 54(3), 841862. doi: $10.1080 / 02724980042000381$

Sherrill, C. (1986). Adapted physical education and recreation: A multidisciplinary approach: WC Brown Publishers.

Silverman, S. (1985). Relationship of Engagement and Practice Trials to Student Achievement. Journal of Teaching in Physical Education, 5(1), 13-21.

Silverman, S. (1991). Research on teaching in physical education. Research Quarterly for Exercise and Sport, 62(4), 352-364.

Smith, S. L., \& Ward, P. (2006). Behavioral interventions to improve performance in collegiate football. Journal of Applied Behavior Analysis, 39(3), 385.

Snowman, J., McCown, R., \& Biehler, R. (2009). Psychology applied to teaching: Houghton Mifflin. 
Southard, D. (1998). Mass and velocity: control parameters for throwing patterns. / Parametres de controle de la masse et de la velocite pour les modeles de lancers. Research Quarterly for Exercise \& Sport, 69(4), 355-367.

Strohmeyer, H. S., Williams, K., \& Schaub-George, D. (1991). Developmental sequences for catching a small ball: a prelongitudinal screening. Research Quarterly for Exercise and Sport, 62(3), 257.

Sweeting, T., \& Rink, J. E. (1999). Effects of direct instruction and environmentally designed instruction on the process and product characteristics of a fundamental skill. Journal of Teaching in Physical Education, 18(2), 216-233.

Vollmer, T. R., \& Bourret, J. (2000). An application of the matching law to evaluate the allocation of two-and three-point shots by college basketball players. Journal of Applied Behavior Analysis, 33(2), 137.

Ward, P., \& Carnes, M. (2002). Effects of posting self-set goals on collegiate football players' skill execution during practice and games. Journal of Applied Behavior Analysis, 35(1), 1.

Warren, W. H. (1984). Perceiving affordances: Visual guidance of stair climbing. Journal of Experimental Psychology: Human Perception and Performance, 10(5), 683.

Wehman, P., \& Schleien, S. J. (1981). Leisure programs for handicapped persons: Austin, TX: PRO-ED.

Werner, P. H., \& Rink, J. E. (1989). Case Studies of Teacher Effectiveness in Second Grade Physical Education. Journal of Teaching in Physical Education, 8(4), 280297. 
Wulf, G., Hoess, M., \& Prinz, W. (1998). Instructions for motor learning: differential effects of internal versus external focus of attention. Journal of Motor Behavior, 30(2), 169-179.

Wulf, G., Lauterbach, B., \& Toole, T. (1999). The learning advantages of an external focus of attention in golf. / Avantages, pour l'apprentissage du golf, d'une attention focalisee sur l'effet de l'action. Research Quarterly for Exercise \& Sport, $70(2), 120-126$.

Wulf, G., McNevin, N., \& Shea, C. (2001). The automaticity of complex motor skill learning as a function of attentional focus. The Quarterly Journal of Experimental Psychology Section A, 54(4), 1143-1154.

Zachry, T., Wulf, G., Mercer, J., \& Bezodis, N. (2005). Increased movement accuracy and reduced EMG activity as the result of adopting an external focus of attention. Brain Research Bulletin, 67(4), 304-309. 